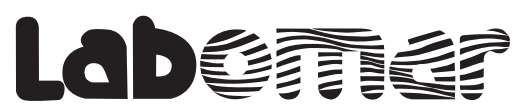

Arquivos de Ciências do Mar

\section{PROCESSOS SEDIMENTARES SAZONAIS E ANÁLISE DA FRAÇÃOO ARENOSA NO SISTEMA AMBIENTAL DO SUESTE, FERNANDO DE NORONHA, ESTADO DE PERNAMBUCO}

\author{
Seasonal sedimentary processes and the coarse fraction \\ analysis in Sueste Bay, Fernando de Noronha, Pernambuco \\ Roberto L. Barcellos ${ }^{1}$, Sayonara R. R. M. Lins ${ }^{2}$, Clemente Coelho Jr. ${ }^{3}$, Paulo E. P. F. Travassos ${ }^{4}$
1 Professor Adjunto IV, Universidade Federal de Pernambuco. E-mail: roberto.barcellos@ufpe.br
${ }^{2}$ Mestranda, Universidade Federal de Pernambuco. E-mail: sayonararaiza@gmail.com
${ }^{3}$ Professor Adjunto, Universidade de Pernambuco. E-mail: clemente.coelhojr@biomabrasil.org.brasil
${ }^{4}$ Professor Adjunto, Universidade Federal Rural de Pernambuco. E-mail: p.travassos@depaq.ufrpe.br
}

\section{RESUMO}

O arquipélago de Fernando de Noronha é o topo de uma montanha vulcânica extinta, possui 21 ilhas e está localizado a $540 \mathrm{~km}$ de Recife-PE, no Atlântico Sul Equatorial $\left(4^{\circ} \mathrm{S} / 32^{\circ} \mathrm{W}\right)$. Devido à construção de uma barragem e uma estrada, a principal entrada de água doce para o sistema ambiental da baía do Sueste foi reduzida nos últimos anos, prejudicando o comportamento hidrológico e morfodinâmica da praia. O objetivo da pesquisa é a avaliação da análise da fração arenosa como uma ferramenta para o refinamento de dados sedimentológicos dos sedimentos superficiais do sistema ambiental do Sueste (praia, manguezal, laguna, dunas e baía), localizado no sudeste da ilha principal. Foram coletadas 146 amostras de sedimentos superficiais em sete trabalhos de campo sazonais entre os anos de 2010/2011. Os métodos de pesquisa incluem a análise da fração arenosa, granulométrica, do carbonato de cálcio e da matéria orgânica elementar e isotópica. As amostras coletadas foram, predominantemente, de areia fina, bem a moderadamente selecionadas e bioclásticas, apresentando alto teor carbonático ( $>90 \%$ em $83,5 \%$ das amostras). A análise da fração arenosa indicou uma homogeneidade espacial e temporal dos grãos, apresentando predominantemente índices BM de 0,80-0,85 indicando forte influência marinha nos processos sedimentares atuais, sendo composto principalmente de fragmentos de conchas de moluscos e corais. Os valores gerais dos dados obtidos foram também indicados na origem oceânica da matéria orgânica sedimentar $\left(\mathrm{C} / \mathrm{N}<12\right.$ e $\delta^{13} \mathrm{C}>$ $19 \%$ PDB) e nas características erosivas dos perfis praiais.

Palavras-chave: ilha oceânica, baía costeira, sedimentos biogênicos, sazonalidade, fração arenosa, matéria orgânica, morfodinâmica.

Recebido em 25 set 2015

Aceito em 20 out 2016

Publicado online 31 mai 2017 


\begin{abstract}
The Fernando de Noronha archipelago is top of an extinct volcanic mountain, has 21 volcanic islands and is located $540 \mathrm{~km}$ from Recife-PE, in the south equatorial Atlantic ( $\left.4^{\circ} \mathrm{S} / 32^{\circ} \mathrm{W}\right)$. Due to the building of a dam and a road, the main freshwater input to the mangrove and bay of Sueste has been drastically reduced in the last years, affecting the hydrology and morphodynamics of the beach. The objective of the research is to evaluate the analysis of the sandy fraction as a tool to refine the sedimentary data of surface sediments from Sueste bay system (beach, mangrove, lagoon, dune and bay), located in the southern coast of the main island. A collection of 146 surface sediments were sampled in seven seasonal field works in 2010/2011. The research methods included coarse fraction, grain-size, calcium carbonate, elemental and isotopic organic matter analysis. The samples are predominantly sandy, moderately well sorted and bioclastic, with high carbonate contents (>90\% in $83.5 \%$ of the samples). The coarse fraction analysis indicated a spatial and temporal homogeneity of the grains, presenting predominantly the $M B$ rate of 0.80-0.85 and indicating strong marine influence in the modern sedimentary processes, being mainly composed by fragments of mollusks, shells and corals. The general obtained data values show a strong marine influence in the sedimentary organic matter $\left(C / N<12\right.$ e $\delta^{13} C>-19 \%$ PDB $)$ and in the erosive character of the beach profiles.
\end{abstract}

Keywords: oceanic island, coastal bay, biogenic sediments, seasonality, coarse fraction, organic matter, morphodinamic.

\title{
INTRODUÇÃO
}

Ambientes de sedimentação constituem unidades espaciais nas quais parâmetros físicos, químicos e biológicos condicionam o desenvolvimento de um corpo sedimentar e são suficientemente constantes para formar um depósito característico (Shepard \& Moore, 1954; Pettijohn, 1975).

Os sedimentos depositados em áreas costeiras são resultantes da interação entre o aporte de material terrígeno continental ou insular e os sedimentos autóctones, principalmente de origem biogênica, de plataformas continentais ou insulares (Johnson \& Baldwin, 1996). Estes depósitos sedimentares guardam em si registros da história evolutiva desse ambiente de transição e de seu comportamento atual, fornecendo parâmetros para a compreensão dos processos que nele ocorrem e de suas relações ecológicas.

O conhecimento dos processos sedimentares em regiões costeiras e marinhas rasas com base nas características dos sedimentos têm sido, há décadas, limitado a diagramas faciológicos ternários (Shepard, 1954; Pejrup, 1988; Flemming, 2000), bem como à interpretação dos parâmetros estatísticos de Folk \& Ward (1957) relacionados à granulometria (diâmetro médio, grau de seleção, assimetria e curtose). Além dos parâmetros composicionais, como de assembléias de minerais pesados e foraminíferos bentônicos, conteúdos de carbonatos e de matéria orgânica (elementar e isotópica), dentre outros proxies. No entanto, em determinados casos os parâmetros de granulação não refletem as condições que levam à sedimentação de expressivas quantidades de materiais não litoclásticos, tais como fragmentos de origem carbonática ou vegetal (Mahiques et al., 1998; Barcellos \& Furtado, 2001). Isto ocorre principalmente em amostras que apresentam distribuições bimodais e que acabam por induzir a interpretações equivocadas sobre a dinâmica sedimentar da área transicional estudada, sendo esta costeira ou marinha. 
A análise da fração arenosa, "coarse fraction analysis", foi proposta por Shepard \& Moore (1954) como uma técnica complementar simples, que pode auxiliar nas interpretações baseadas nos parâmetros granulométricos, sendo utilizada originalmente para diferenciação entre ambientes costeiros e de plataforma continental.

Nesta pesquisa é utilizada uma técnica análoga, a partir da adaptação de Mahiques (1987) da análise proposta por Shepard \& Moore (1954). Consiste na identificação e contagem dos grãos sedimentares constituintes das frações arenosas retidas nas peneiras de malhas $0,500 \mathrm{~mm}(1 \varnothing)$ e $0,250 \mathrm{~mm}(2 \varnothing)$, indicativos de transporte por tração e saltação, respectivamente. Esta análise permite obter um parâmetro de avaliação da influência continental nos sedimentos marinhos pela detecção dos tipos de fragmentos contidos nas amostras selecionadas. Mahiques et al. (1998) inferem que este tipo de análise pode ser usada como técnica adicional ao estudo da granulometria ou de análise química, permitindo uma caracterização de subambientes em áreas costeiras.

Este trabalho tem como objetivo a aplicação dos dados obtidos por meio da análise da fração arenosa como um instrumento auxiliar para a determinação das variações espaço-temporais da dinâmica de fundo do sistema ambiental do Sueste (laguna-mangue, duna, praia e baía) Arquipélago de Fernando de Noronha (AFN) (PE), bem como a avaliação do grau de influência terrígena insular ou marinha no aporte para os sedimentos da área.

\section{ÁREA DE ESTUDO}

A área de estudo é o Arquipélago de Fernando de Noronha, em particular, o sistema costeiro da baía do Sueste, localizada na costa meridional da ilha principal. O ecossistema manguezal composto apenas pela espécie Laguncularia recemosa representa o único bosque de mangue em ilha oceânica no Atlântico Sul (Pessenda et al., 2008) e está diretamente conectado à drenagem intermitente do córrego Maceió, que contribui com a água doce necessária à manutenção deste ecossistema. Entretanto, devido à construção da Barragem do Xaréu e da Rodovia BR-363 esta contribuição foi drasticamente reduzida nos últimos anos, afetando seu comportamento hidrológico bem como a morfodinâmica praial (Teixeira et al., 2003; Pessenda et al., 2008).

Em termos gerais, o arquipélago, com $26 \mathrm{~km}^{2}$ e localizado a $4^{\circ} \mathrm{S} / 32^{\circ} \mathrm{W}$ distante 540 $\mathrm{km}$ de Recife (capital de Pernambuco) (Figura 1), é constituído por 21 ilhas que emergem de uma plataforma insular com diâmetro de $10 \mathrm{~km}$ e limite em torno da isóbata de $100 \mathrm{~m}$, formada pelas variações glacio-eustáticas quaternárias (Teixeira et al., 2003). Representa o topo do cone vulcânico de uma montanha submarina (hot-spot), de idade entre 1,3 e 12,0 Ma, cuja base com $74 \mathrm{~km}$ de diâmetro se situa a cerca de $4200 \mathrm{~m}$ de profundidade no assoalho oceânico (Almeida, 2006). O clima do arquipélago é tropical oceânico (Awi-Köppen $\approx$ $25^{\circ} \mathrm{C} / 1400 \mathrm{~mm}$ ) com grande variabilidade interanual, caracterizado por uma estação seca de agosto a janeiro (verão), e úmida de março a julho (inverno) (Teixeira et al., 2003). Está sujeita a um regime de mesomarés com amplitudes médias de 2,6m nas sizígias e de 1,1m na quadratura (DHN, 2009). E como Fernando de Noronha localiza-se no Atlântico SulEquatorial, está submetido à influência da Corrente Central Sul-Equatorial (cCSE) e ao predomínio dos ventos alísios de SE com velocidade média de $6,6 \mathrm{~ms}^{-1}$, exibindo maior intensidade de julho a setembro $\left(11 \mathrm{~ms}^{-1}\right)$ (Manso et al., 2011). Durante o verão, ventos dos quadrantes sudeste e leste sopram por $50 \%$ e $35 \%$ do tempo respectivamente (Hoflich, 1984). As ondas predominantes são oriundas do Hemisfério Norte (N/NW) alcançando 4-5m de altura e 18-2 0s de período nos swells mais energéticos (Teixeira et al., 2003). No 
inverno é observada uma intensificação nos ventos de SE, com $70 \%$ de frequência, enquanto em $25 \%$ do tempo os ventos são de E. As ondas predominantes no inverno são de SE e com 1,6m de altura em média (Hoflich, 1984), atingindo a porção sul da ilha ("Mar de Fora"), onde o Sistema sedimentar do Sueste está localizado.

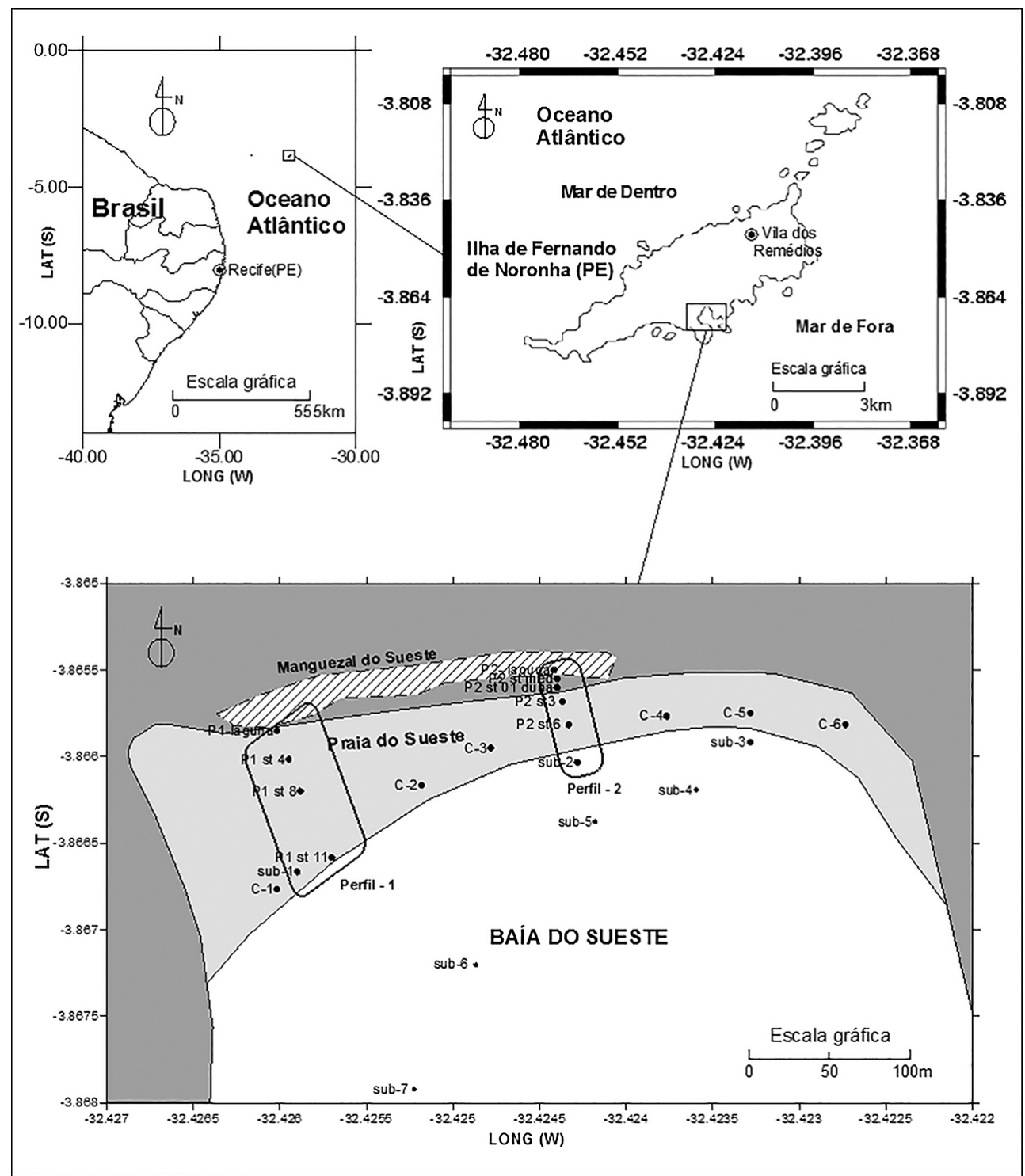

Figura 1 - Localização do arquipélago de Fernando de Noronha, das estações e de coleta e dos perfis topográficos (nos retângulos) no sistema sedimentar do Sueste.

A praia do Sueste, no limite costeiro $\mathrm{N}$ da baía, apresenta 450 m de extensão e largura que varia de cerca de 80-100 m em sua porção W e de a 30-50 m no lado E. Adjacente à praia existe um cordão de dunas parcialmente vegetadas e que a separa do mangue, exceto no setor da desembocadura do córrego Maceió, que por sua vez apresenta as características de um estuário cego de acordo com a classificação de Fairbridge (1980). O manguezal com 0,89 ha é associado a um corpo lagunar posicionado a 2,40m acima do nível do mar, com cerca de 300m de comprimento e 25 de largura, encaixado paralelamente entre o cordão de dunas frontal (2,5 m de altura) e cordão de dunas mais antigo $(8-10 \mathrm{~m})$ à retaguarda da 
pequena planície costeira 0,125 km² (Barcellos et al., 2013). De acordo com Barcellos et al. (2016) a reentrância costeira associada à planície é denominada de baía do Sueste, o ambiente litorâneo mais abrigado do arquipélago e que possui águas rasas $(<2 \mathrm{~m})$, com diversos bancos de recifes coralíneos e sedimentos predominantemente biogênicos oriundos de organismos marinhos (algas, espongiários, briozoários e moluscos). A baía apresenta diversos obstáculos que intervêm em sua dinâmica de circulação interna pela redução da ação de ondas, como a presença de ilhas a S/SE (Chapéu do Sueste e Cabeluda) e promontórios a W e E (Ponta das Caracas e Morro do Madeira), que criam uma constrição limitando a entrada da Baía do Sueste a 300 m de largura e com canal de circulação de 5-10 m de profundidade de apenas $50 \mathrm{~m}$ de largura. Esta constrição gera correntes de deriva litorânea convergentes, associadas à ação de ondas difratadas e refratadas na entrada da baía, que de acordo com Barcellos et al. (2011) acarretam na acumulação de sedimentos na porção W da praia, área onde se localiza a desembocadura do córrego Maceió, o manguezal e a laguna do Sueste.

Os subambientes sedimentares que compõem a baía do Sueste estão representados na Figura 2.

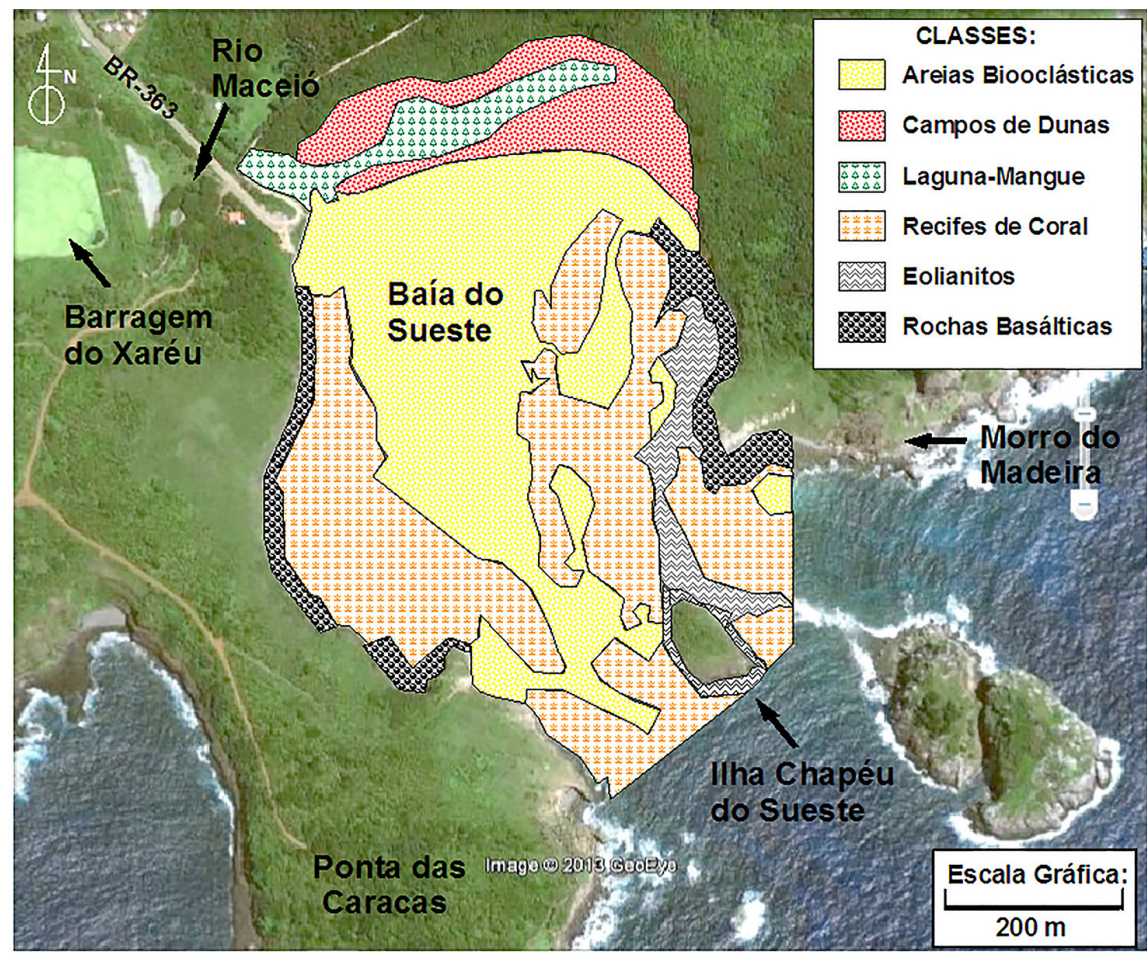

Figura 2 - Subambientes e Geohabitats no sistema ambiental do Sueste.

(Fonte: Google Earth adaptado de Barcellos et al., 2013 e Barcellos et al., 2016).

\section{MATERIAIS E MÉTODOS}

Para caracterização sedimentológica e avaliação da dinâmica sedimentar sazonal local, foram efetuadas 7 campanhas sazonais, em condições de maré de sizígia (Lua cheia e nova), durante as estações de outono-inverno, período de chuvas, e verão-primavera, período de seca, no sistema sedimentar do Sueste (Laguna-Mangue, Duna, Praia e Baía Costeira). 
Do total de 146 amostras geradas, 36 foram coletadas, em janeiro e junho de 2010 (FN-I e FN-III); 110 amostras foram coletadas em abril e outubro de 2010, março, julho e outubro de 2011(FN-II, FN-IV, FN-V, FN-VI e FN-VII) (vide Figura 1). Em cada campo realizado, cerca de $200 \mathrm{~g}$ de sedimentos foram ensacados para a realização de análises granulométricas e geoquímicas. Paralelamente às coletas de sedimentos superficiais foi efetuada nas sete campanhas a caracterização das condições morfodinâmicas do sistema sedimentar do Sueste (Laguna-Mangue, Duna, Praia e Baía Costeira) por meio do levantamento de dois perfis transversais à praia, conforme descrito por Muehe (1996) com o uso de nível e estádia. As cotas foram obtidas, em geral, de 5 em $5 \mathrm{~m}$, a partir de um ponto pré-estabelecido (margem interna do canal do mangue), até atingir a antepraia (1,0 m de profundidade). A depender da presença de feições morfológicas de destaque nos perfis (ex.: início da vegetação permanente, campo de dunas, bermas de pós-praia e escarpas, terraços de maré baixa, linha d'água ou qualquer feição de relevo positiva ou negativa), a distância entre as cotas foram alteradas para representar as feições no perfil. Os marcos de referência (RN) escolhidos foram determinados a partir de referências fixas (caules de árvores marcadas) devidamente posicionados por GPS (RN P1: 351,951'S; 32²5,561' W / P2: 351,936'S; $\left.32^{\circ} 25,464^{\prime} \mathrm{W}\right)$, distando o P1 180m do P2. Posteriormente, os perfis foram ajustados ao nível médio do mar com o uso das tábuas de marés da Diretoria de Hidrografia e Navegação (DHN). As mudanças verticais nos perfis praiais foram obtidas a partir da sobreposição dos mesmos nos meses subsequentes, sendo representados graficamente em várias combinações para o acompanhamento da variação morfológica dos mesmos, apresentando variações verticais (acresção/erosão) da face praial nas porções W e E da Praia do Sueste. Para o cálculo do volume de sedimentos presente nos perfis, foi adotado um comprimento padrão para cada perfil, visando tornar os volumes calculados comparáveis entre si. Posteriormente, foi determinada a área abaixo de cada perfil, pelo cálculo geométrico de cada seção, multiplicando o valor da área em metros quadrados por $1 \mathrm{~m}$. Mantendo-se o valor da área, foi possível obter o volume de areia por metro linear de praia, expresso em metros cúbicos por metro $\left(\mathrm{m}^{3} / \mathrm{m}\right)$.

No laboratório as amostras foram secas em estufa a $50^{\circ} \mathrm{C}$, sendo realizadas as análises granulométricas, de acordo com o método descrito em Suguio (1973), a análise da fração arenosa, como proposta por Shepard \& Moore (1954) e modificada por Hubert (1971), Mahiques (1987) e Mahiques et al. (1998), e as análises geoquímicas do sedimento: conteúdo em carbonato de cálcio e de matéria orgânica total determinados a partir da diferença, em peso seco, antes e após ataque com solução de $\mathrm{HCl}$ a $10 \%$ e de $\mathrm{H}_{2} \mathrm{O}_{2}$ a $10 \%$, respectivamente (Carver, 1971 apud Suguio, 1973; Müller, 1967 apud Suguio, 1973). Por fim foi efetuada a análise de carbono orgânico e nitrogênio total (C e $\mathrm{N}$ elementares), razão elementar $\mathrm{C} / \mathrm{N}$ e valores das razões isotópicas de carbono $\left(\delta^{13} \mathrm{C}\right)$. Após um tratamento preliminar da amostra para a eliminação do $\mathrm{CaCO}_{3}$ existente, conforme descrito em Hedges \& Stern (1984), a composição elementar $(\mathrm{C} \mathrm{e} \mathrm{N})$ e isotópica de carbono $\left(\delta^{13} \mathrm{C}\right)$ foi determinada pela combustão automática da amostra em um analisador elementar Carlo Erba (CHN1110), acoplado a um espectrômetro de massa Finnigan Delta Plus. As amostras foram queimadas em meio oxidante, e os gases produzidos separados por cromatografia gasosa, purificados e carreados por um fluxo contínuo de Hélio. $\mathrm{O}$ valor das razões isotópicas de carbono $\left(\delta^{13} \mathrm{C}\right)$ (em partes por mil) é referido ao PDB (Pee Dee Belemnite).

Conforme a obtenção dos dados em laboratório foram elaboradas tabelas e gráficos, mapas de distribuição e o cálculo dos volumes de sedimentos (Surfer for Windows 9.0) dos parâmetros estudados. 


\section{RESULTADOS E DISCUSSÃO}

As tabelas referentes aos resultados dos parâmetros sedimentares e geoquímicos estão anexados ao fim do artigo (Apêndice A). E no caso dos dados relativos às análises da fração arenosa no Apêndice B.

\section{Processos sedimentares sazonais}

De acordo com o diagrama de fácies sedimentares de Shepard (1954), as amostras coletadas em 2010/11 são areias em geral (Figura 3), apresentando diâmetro médio areia fina (> 99,0\% de areia em $87,9 \%$ das amostras), sendo de bem a moderadamente selecionadas e bioclásticas (Larssoneur et al., 1982) com altos teores de carbonato de cálcio $\left(\mathrm{CaCO}_{3}\right)$, variando de 73,8 a $96,0 \%, 75,7$ a $97,1 \%, 51,8$ a $95,6 \%, 46,5$ a $96,3 \%, 44,1$ a $94,8 \%, 41,9$ a $95,2 \%$ e 36,7 a 95,5\%, para janeiro, abril, junho, outubro de 2010 e março, julho e outubro de 2011, respectivamente, prevalecendo conteúdos maiores que 90,0\% em 85,1\% das amostras. Estes dados indicam uma grande homogeneidade sedimentar com amostras em todos os subambientes apresentando características arenosas e granulação fina média de origem predominantemente biogênica (Figura 4a). Excetuam-se as amostras da laguna também compostas de lamas terrígenas de origem insular, pobremente selecionadas e de composição biolitoclástica (Figura $4 b$ ).

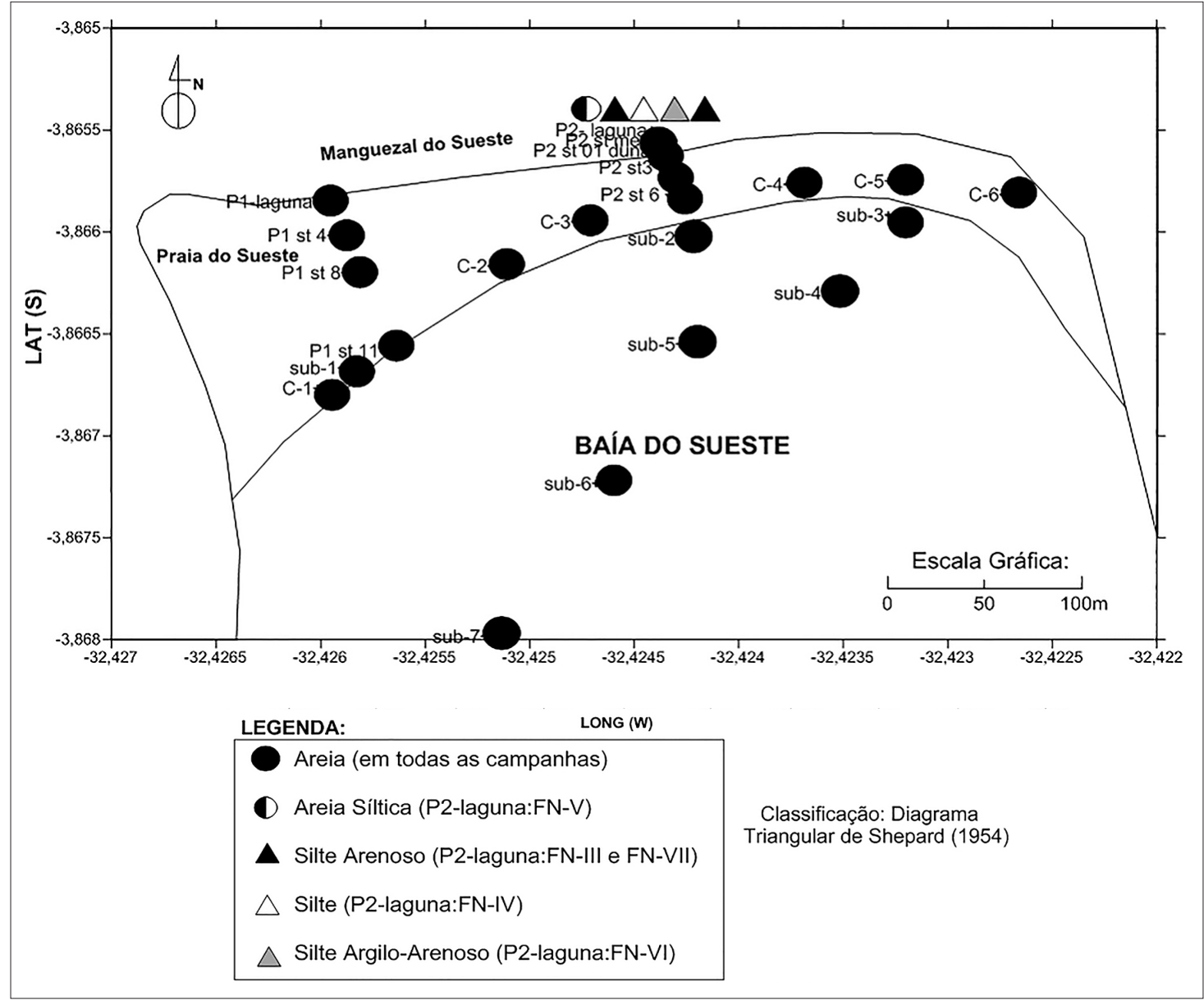

Figura 3 - Classificação dos sedimentos das campanhas FN-I a FN-VII com base no diagrama de fácies sedimentares de Shepard (1954) (Lins, 2016). 


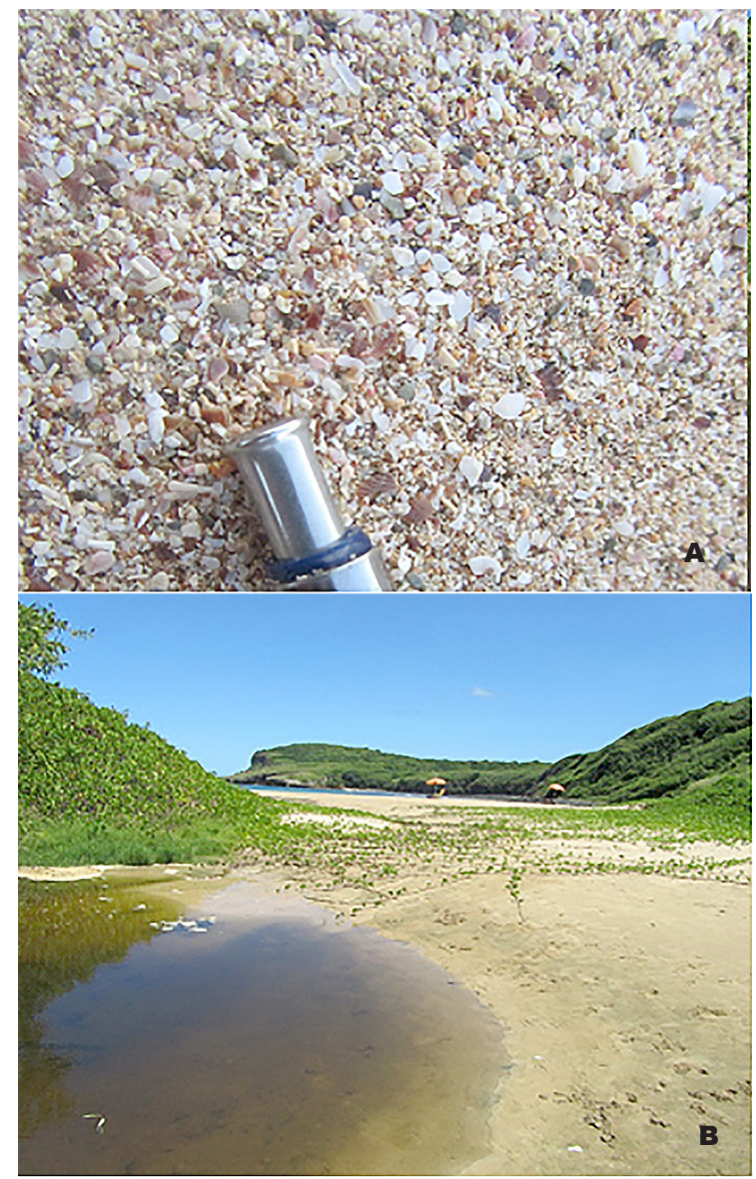

Figura $4 \mathrm{a}$ e $4 \mathrm{~b}$ - Sedimentos típicos da baía, praia e dunas à esquerda (a) e lagunares com a presença de lamas terrígenas insulares em suspensão na desembocadura da laguna parcialmente seca no fim do verão (b)

(Fotos: Roberto Barcellos em 28/10/2011 e 21/03/2011).
Os resultados mostram um padrão de distribuição espacial para os períodos estudados, caracterizado por subambientes com grãos terrígenos (fragmentos de plantas superiores, minerais pesados e fragmentos de rocha) associados às rochas fontes, laguna e córrego Maceió e apresentado teores de $\mathrm{CaCO}_{3}$ e de matéria orgânica mais baixos no lado oeste da praia. A matéria orgânica na porção oeste tende a ser de origem mista e marinha. No lado leste, para os períodos estudados, os sedimentos são arenosos bem selecionados e compostos principalmente por fragmentos de $\mathrm{CaCO}_{3}$ e maiores teores de matéria orgânica de origem marinha (Barcellos et al., 2011; Barcellos et al., 2016).

Em geral, esses sedimentos são mais finos (areia fina: 2,00 a 3,00 $\varphi-0,250 \mathrm{~mm}$ ) do que os sedimentos encontrados nas praias expostas e muito dinâmicas, localizadas na costa norte da ilha principal (Praias da Cacimba do Padre, Boldró, Conceição e Sancho), compostos por areias médias $(1,00$ a $2,00 \varphi-0,500$ $\mathrm{mm})$ bem a moderadamente selecionadas (Manso et al., 2011).

Apesar da homogeneidade de areias finas bioclásticas moderadamente selecionadas, são observadas diferenças espaciais e temporais entre os sedimentos da porção oeste e leste da praia, bem como em cada compartimento do sistema praial do Sueste (laguna-mangue/duna/praia/baía).

A análise da fração arenosa, ao refinar os dados granulométricos, indicou também uma grande homogeneidade espacial e temporal nos grãos constituintes nas frações 0,500 mm e 0,250 mm (Figuras 5 a 8). Com valores predominantes do índice B.M (Mahiques et al., 1998) por volta de 0,80-0,85, indicativos de influência marinha no processo sedimentar atual. Valores do índice B.M. próximos a $-1,0$ são indicativos de aporte sedimentar essencialmente continental.

O conjunto vulcânico insular não inclui rochas ricas em leucita, o principal constituinte terrígeno de sedimentos de praia. Somado à ausência de rios perenes, a natureza das areias de suas praias, dunas e plataforma é principalmente bioclástica. Análises petrográficas do Arenito Caracas, paleodunas de 42 a 22.000 AP e formação que compõe a ilha chapéu do Sueste, indicaram a presença de fragmentos de algas coralíneas, corais, braquiópodes, foraminíferos e poucos artrópodes. Muito similares à composição dos sedimentos praiais atuais, formados por fragmentos de conchas, de ouriços, corais, algas e poucos minerais silicáticos ou metálicos pesados, além de raros fragmentos rochosos vulcânicos (Teixeira et al., 2003).

Esses estudos corroboram com o observado na análise da fração arenosa efetuada, que indicaram o predomínio de grãos constituintes de origem biogênica marinha, no caso 
fragmentos de moluscos, corais e foraminíferos. Similar ao também observado em estudos efetuados em outras ilhas oceânicas tais como Cocos Island (Oceano Índico) (Kench, 1997), Oahu e Maui no Havaí (Norcross et al., 2002; Rooney \& Fletcher, 2004) e Atol das Rocas (Kikuchi \& Leão, 1997; Kikuchi, 1999; Pereira et al., 2010). São muitos distintos dos sedimentos essencialmente litogênicos da plataforma continental de São Paulo (Mahiques, 1992; Mahiques et al., 1998; Barcellos, 2000; Barcellos \& Furtado, 2001).

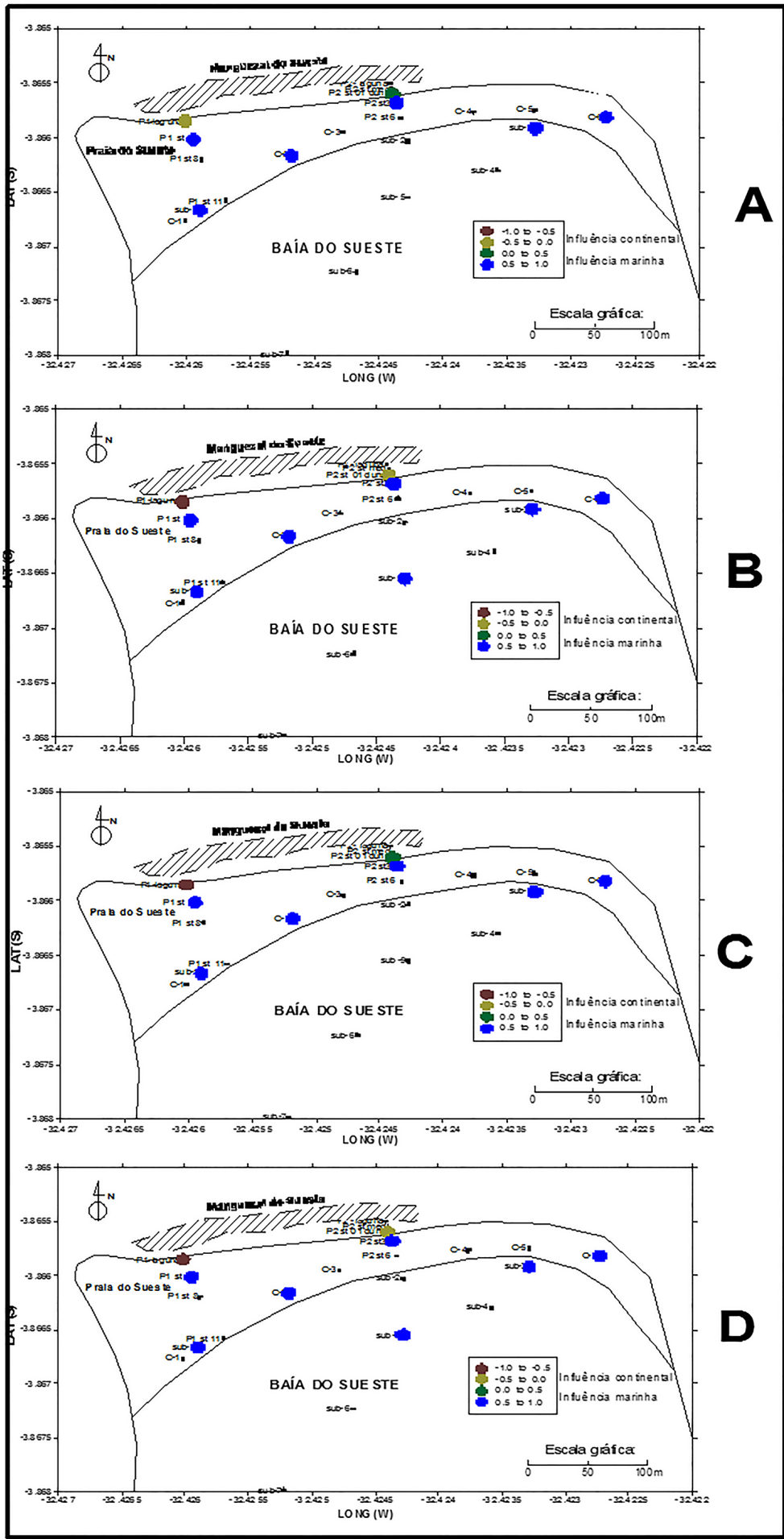

Figura 5 - Índice de biogênicos marinhos (B.M.) da fração $0,500 \mathrm{~mm}$ (A-Jan, B-Abr, C- Jun, D- Out.) - 2010.

Fonte: (Lins, 2016). 
Figura 6 - Índice de biogênicos marinhos (B.M.) da fração $0,250 \mathrm{~mm}$ (A- Jan, BAbr, C- Jun, D- Out.) - 2010. Fonte: (Lins, 2016).

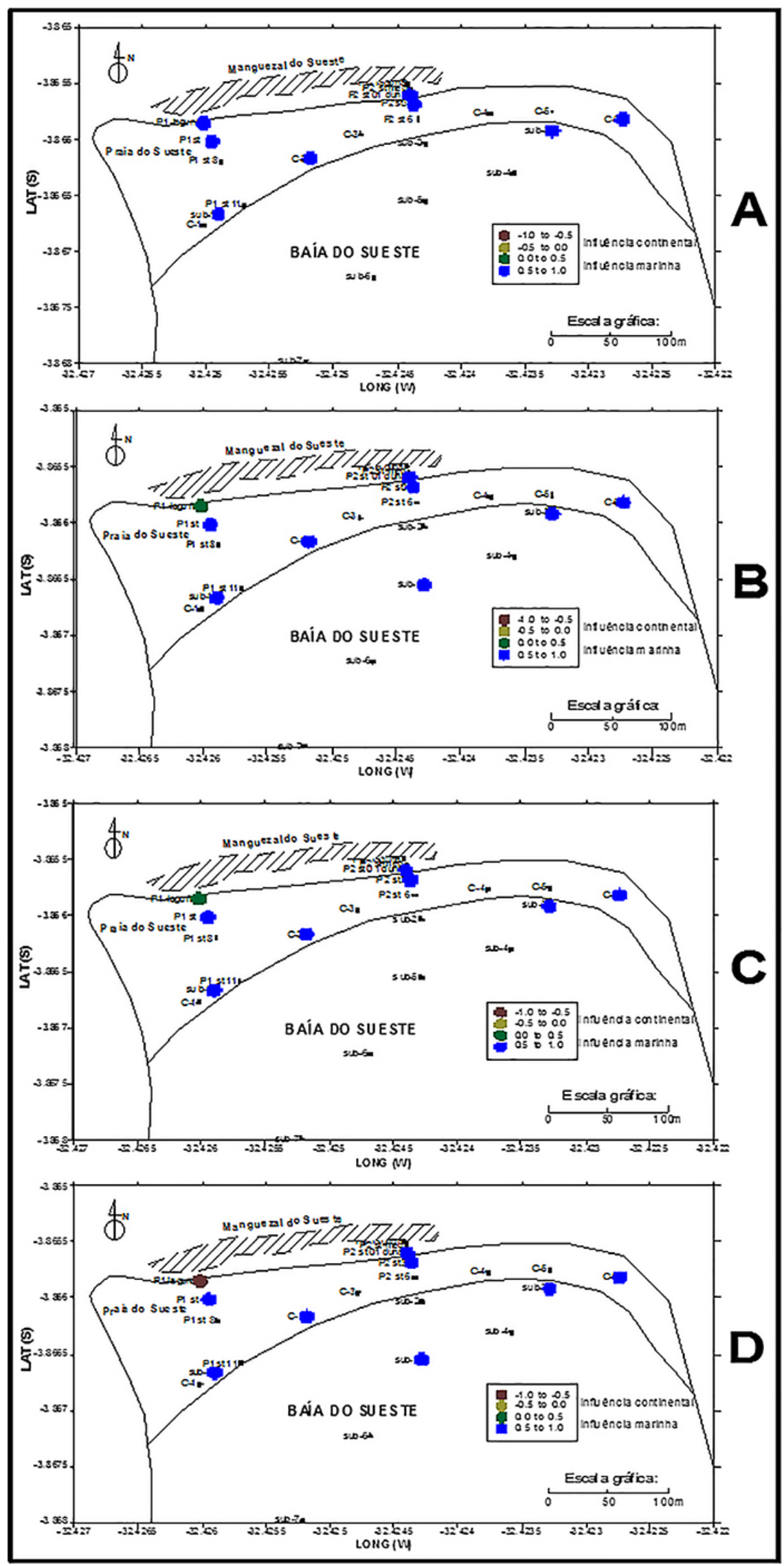




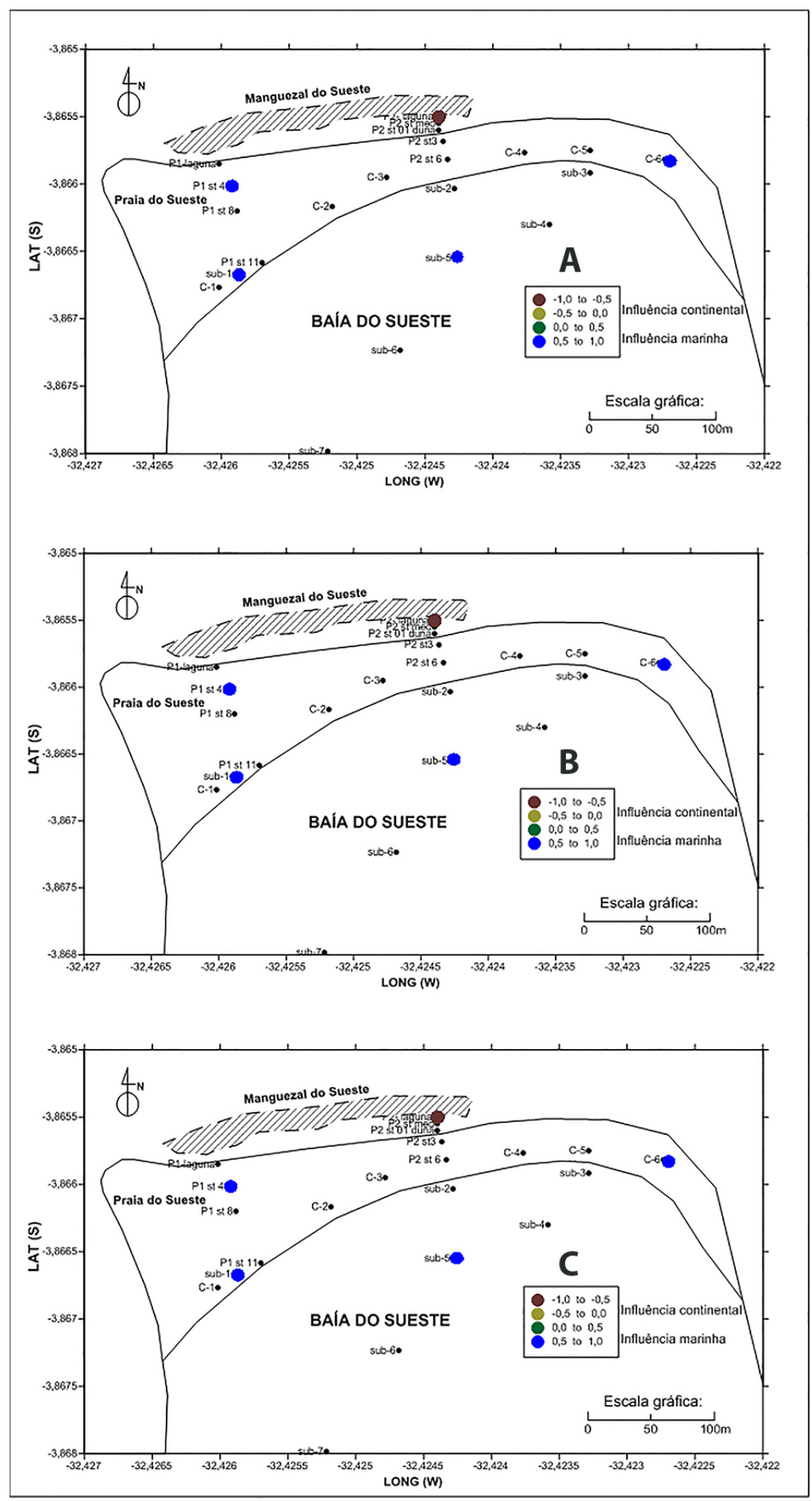

Figura 7 - Índice de biogênicos marinhos (B.M.) da fração 0,500 mm (A- Mar, B- Jul, C-Out.) - 2011.

Fonte: (Lins, 2016). 

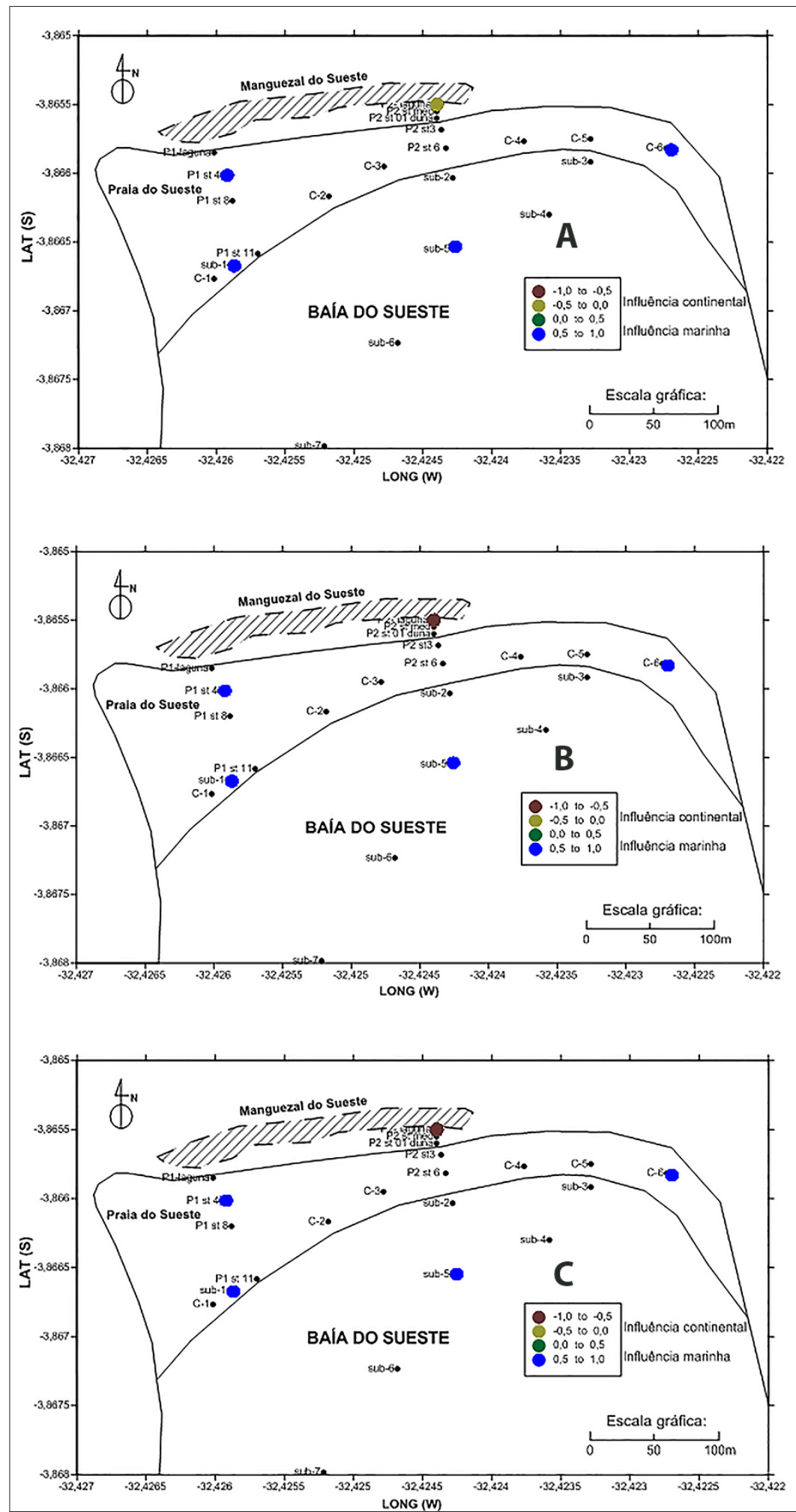

Figura 8 - Índice de biogênicos marinhos (B.M.) da fração 0,250 mm (A- Mar, B- Jul, C-Out.) - 2011. Fonte: (Lins, 2016). 
Os resultados complementares trazidos pela análise da fração arenosa também indicam uma maior influência terrígena na porção oeste do sistema refletida por valores menores do índice BM, com maior contribuição de fragmentos de rocha e vegetais nas estações P2 St-laguna, P2-St1, P1-St4 e Sub-1, por estarem associados à proximidade de rochas fonte (matacões presentes na face praial) e às desembocaduras do sistema lagunar e do rio Maceió. Nas estações P2 St-laguna e P2-St1 há predominância de fragmentos vegetais e fragmentos de rochas, enquanto que nas estações P1-St4 e Sub-1 possuem, em geral, apenas fragmentos de rochas (exceto nas amostras de Janeiro (FN-I), onde a estação P1-St4 apresentou presença de fragmentos vegetais).

A estação sub-5 também indicou uma maior influência terrígena insular, pela presença significativa de fragmentos de rocha $(>22,9 \%)$ aí depositados devido às condições de maior hidrodinâmica, derivadas da concentração da energia de ondas nesta região da Baía do Sueste e pela presença dos afloramentos e escarpas rochosas do Morro do Madeira a leste.

Por outro lado, sedimentos essencialmente biogênicos com valores do índice B.M. maiores, em média que 0,88 , são encontrados na face praial superior da porção leste da praia (St C-6) e na porção central da praia (St Sub-3), portanto, nas porções mais distantes das áreas fontes de sedimentos terrígenos.

\section{Dinâmica Morfossedimentar}

Os perfis topográficos da praia revelaram processos de erosão e acresção sazonal devido a fatores oceanográficos e climáticos (Figuras 9 e 10). Estes também mostram um processo de assoreamento em curso na laguna e mangue do Sueste. A Tabela 1 ilustra os volumes de sedimentos contidos nos perfis 1 e 2 , bem como o balanço sedimentar entre os períodos amostrados.

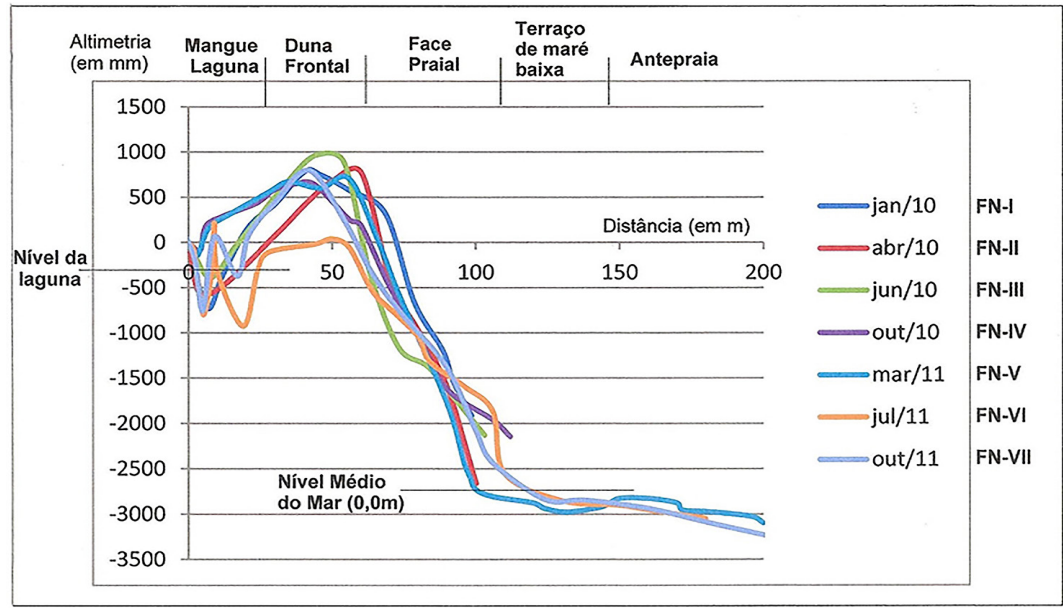

Figura 9 - Perfil topográfico $\mathrm{n}^{\circ} 1$ referente às campanhas FN-I a FN-VII.

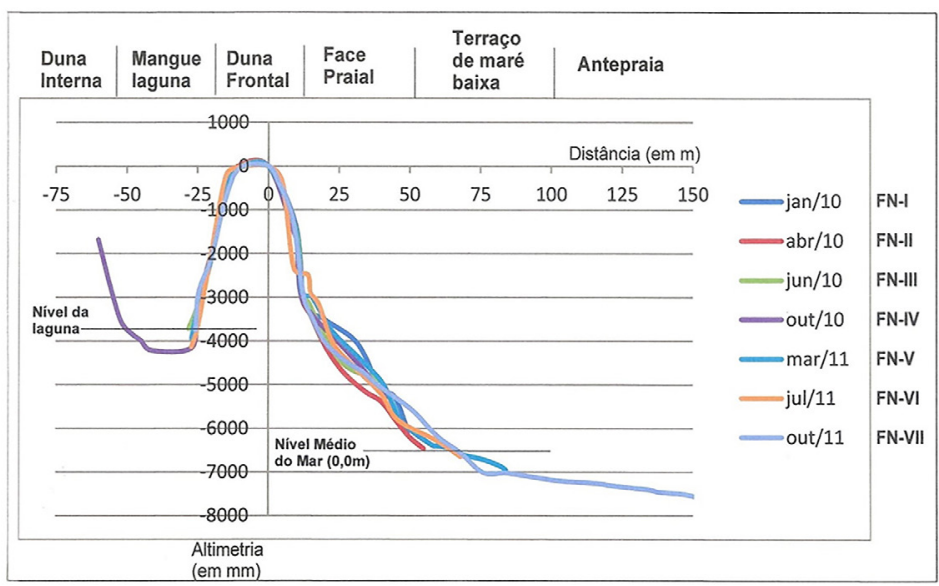

Figura 10 - Perfil topográfico ${ }^{\circ} 2$ referente às campanhas FN-I a FN-VII. 
Tabela 1 - Volumes contidos nos perfis 1 e 2 (em m3/m) e o balanço sedimentar entre as campanhas de coleta FN-I a FN-VII.

\begin{tabular}{|c|c|c|c|c|}
\hline \multirow[b]{2}{*}{ Mês/ano (coleta) } & \multicolumn{2}{|c|}{ Perfil 1} & \multicolumn{2}{|c|}{ Perfil 2} \\
\hline & Vol. m³/m (Perfil 1) & $\begin{array}{c}\text { Balanço Sedimentar } \\
\mathbf{m}^{3} / \mathbf{m}(\mathbf{P 1})\end{array}$ & Vol. $\mathbf{m}^{3} \cdot \mathrm{m}^{-1}$ (Perfil 2) & $\begin{array}{c}\text { Balanço Sedimentar } \\
\mathbf{m}^{3} \cdot \mathbf{m}^{-1}(\mathbf{P} 2)\end{array}$ \\
\hline Jan/10 (FN-I) & 189,6 & - & 186,0 & - \\
\hline $\begin{array}{l}\text { Abr/10 } \\
\text { (FN-II) }\end{array}$ & 168,9 & $-20,7$ & 169,6 & $-16,4$ \\
\hline $\begin{array}{l}\text { Jun/10 } \\
\text { (FN-III) }\end{array}$ & 173,2 & $-16,4$ & 174,9 & $-11,1$ \\
\hline $\begin{array}{l}\text { Out/10 } \\
\text { (FN-IV) }\end{array}$ & 183,7 & $-5,9$ & 175,2 & $-10,8$ \\
\hline $\begin{array}{l}\text { Mar/11 } \\
\text { (FN-V) }\end{array}$ & 187,5 & $-2,1$ & 182,0 & $-4,0$ \\
\hline Jul/11 (FN-VI) & 141,4 & $-48,2$ & 178,2 & $-7,8$ \\
\hline $\begin{array}{l}\text { Out/11 } \\
\text { (FN-VII) }\end{array}$ & 170,8 & $-18,8$ & 173,5 & $-12,5$ \\
\hline
\end{tabular}

Fonte: Barcellos et al. (2016).

O principal fator responsável pela fisiografia da praia por essa deposição e distribuição atual de sedimentos na pós-praia, face praial e antepraia do sistema ambiental do Sueste é o vento ESE (ventos alísios do hemisfério sul). Este padrão acumula sedimentos no lado oeste da praia, que são ocasionalmente removidos para a baía Sueste quando ocorre o rompimento da duna que protege a laguna nos esporádicos eventos de chuva torrenciais, carreando grandes quantidades de água doce e sedimentos para a antepraia e baía do Sueste. O sistema praial de Sueste apresenta um ciclo sazonal de transporte sedimentar, contudo pelos resultados pode-se notar um processo de assoreamento da laguna-mangue e erosão da face praial (no perfil 2). Estando o perfil 2 evidenciando toda a variabilidade sedimentar e morfológica do sistema sedimentar do Sueste, com sedimentos que cortam todos os subambientes de sedimentação existentes nesta porção abrigada da ilha. O perfil 1 indica um padrão anual de acresção e erosão derivadas das forçantes oceanográficas. Sendo os Ventos Alísios o principal fator de distribuição sedimentar na praial, pela acumulação na porção oeste.

Este processo foi observado no P1 em jul/10 (FN-IV), que apresentou um expressivo déficit no balanço sedimentar com uma erosão da ordem de $-48,2 \mathrm{~m}^{3} / \mathrm{m}-46,2 \mathrm{~m}^{3} / \mathrm{m}$, quando comparado a jan/10 (FN-I) e mar/11 (FN-V), respectivamente. A topografia medida na $1^{\text {a }}$ campanha de coleta (FN-I: jan/10) foi praticamente reestabelecida no verão de 2011, apresentando a praia em sua porção $W$ um pequeno padrão erosivo e um déficit no volume de sedimentos entre a campanha de janeiro de 2010 (FN-I) e outubro de 2011 (FN-VII) $\left(-18,8 \mathrm{~m}^{3} / \mathrm{m}\right)$.

Por fim, através dos dados obtidos no momento das coletas de julho/11 (FN-VI) para o P1 e de mar-out/11 (FN V e VII) para o P2, de acordo com a tábua de marés da DHN, foi possível estabelecer a cota 0,0 m do Nível Médio do Mar (NMM) local com relativa precisão. No P1 o NMM encontra-se 2,75 m abaixo da cota altimétrica do RN (P1 st1 laguna), estando a laguna na ocasião a 2,4 m acima do NMM. E no caso do P2, NMM está 6,4m abaixo da cota do RN (P2 st1 duna) e o nível da laguna 3,9 m abaixo deste. O que corrobora os dados do P1, com a laguna estando em torno de 2,5 $\mathrm{m}$ acima do NMM.

\section{Geoquímica espaço-temporal}

A matéria orgânica total (MOT), ilustrada na Figura11, variou de 1,0 a 5,6\% em janeiro (FN-I) e de 0,4 a 11,5\% (FN-II) em abril (Barcellos et al., 2011). Com maiores teores nas amostras do P2 e porção E da praia. As variações sazonais dos teores de matéria orgânica total na entrada da laguna se devem à própria flutuabilidade do nível de água interno a 
esta, que no verão seco expõe subaereamente os sedimentos da desembocadura (Figura 4b). Estes então adquirem um caráter mais arenoso devido ao aporte eólico das areias advindo da face praial, acarretando nas flutuações nos conteúdos de lamas de MOT observados. Os valores das razões elementares $\mathrm{C} / \mathrm{N}$ variaram de 8,8 a 20,8, 6,2 a 17,6, 8,4 a 23,9 e de 8,0 a 21,8 observados para as campanhas FN-I (jan/10), FN-II (abr/10), FN-III (jun/10) e FN-IV (out/10), respectivamente (Figura 12). Para as mesmas campanhas, os conteúdos da razão isotópica $\delta^{13} \mathrm{C}$ observados variaram, respectivamente, de $-28,1$ a $-19,4 \%$ PDB, $-27,4$ a $-17,4 \%$ PDB, $-27,9$ a $-17,6 \%$ PDB e de $-28,3$ a $-17,8 \%$ PDB (Figura 13).

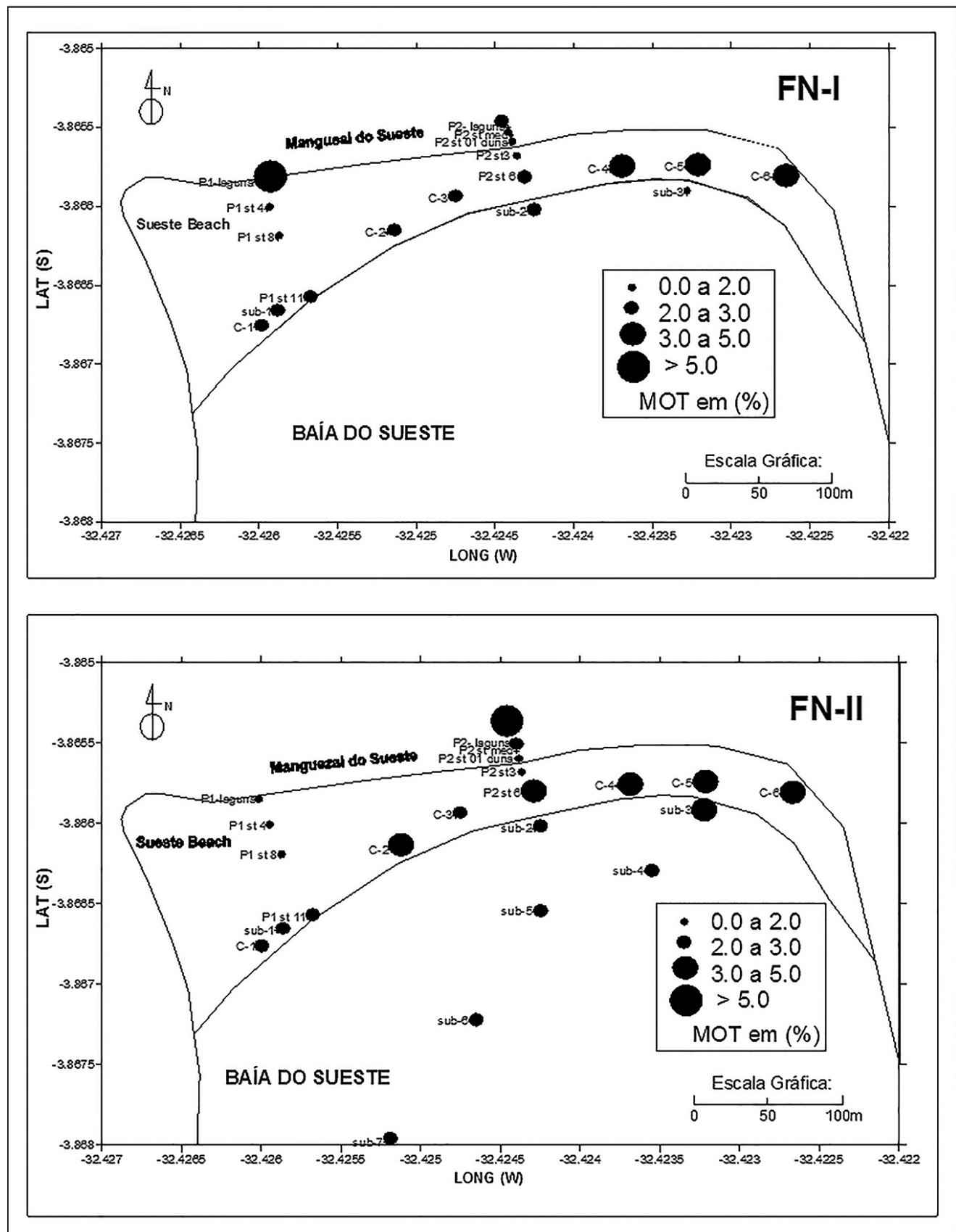

Figura 11 - Conteúdos de matéria orgânica total (em \%) dos sedimentos das campanhas FN-I (jan/10) e FN-II (abr/10) (Barcellos et al., 2011; Barcellos et al., 2016). 

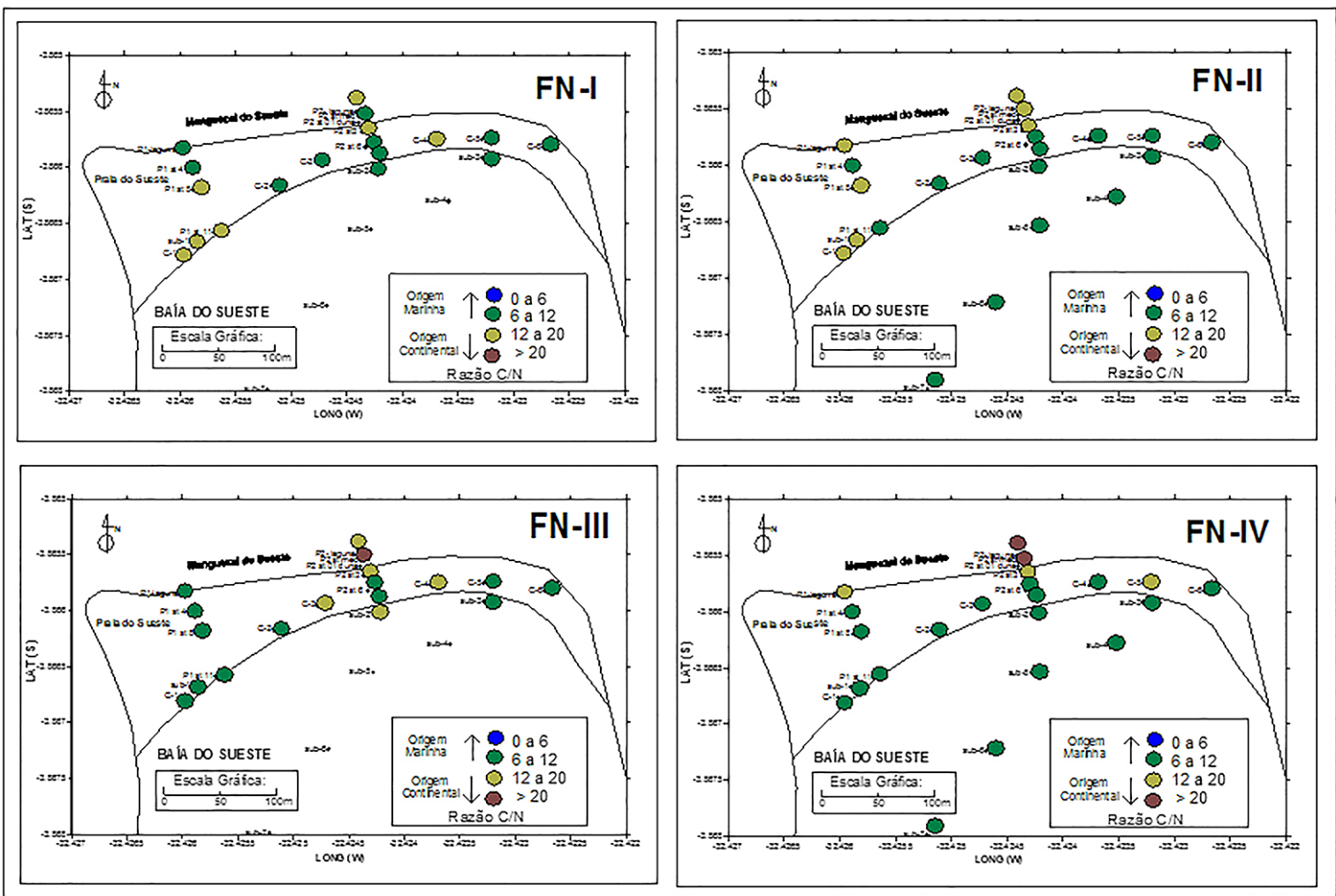

Figura 12-Valores da razão C/N dos sedimentos das campanhas FN-I (jan/10), FN-II (abr/10), FN-III (jun/10) eFN-IV (out/10).
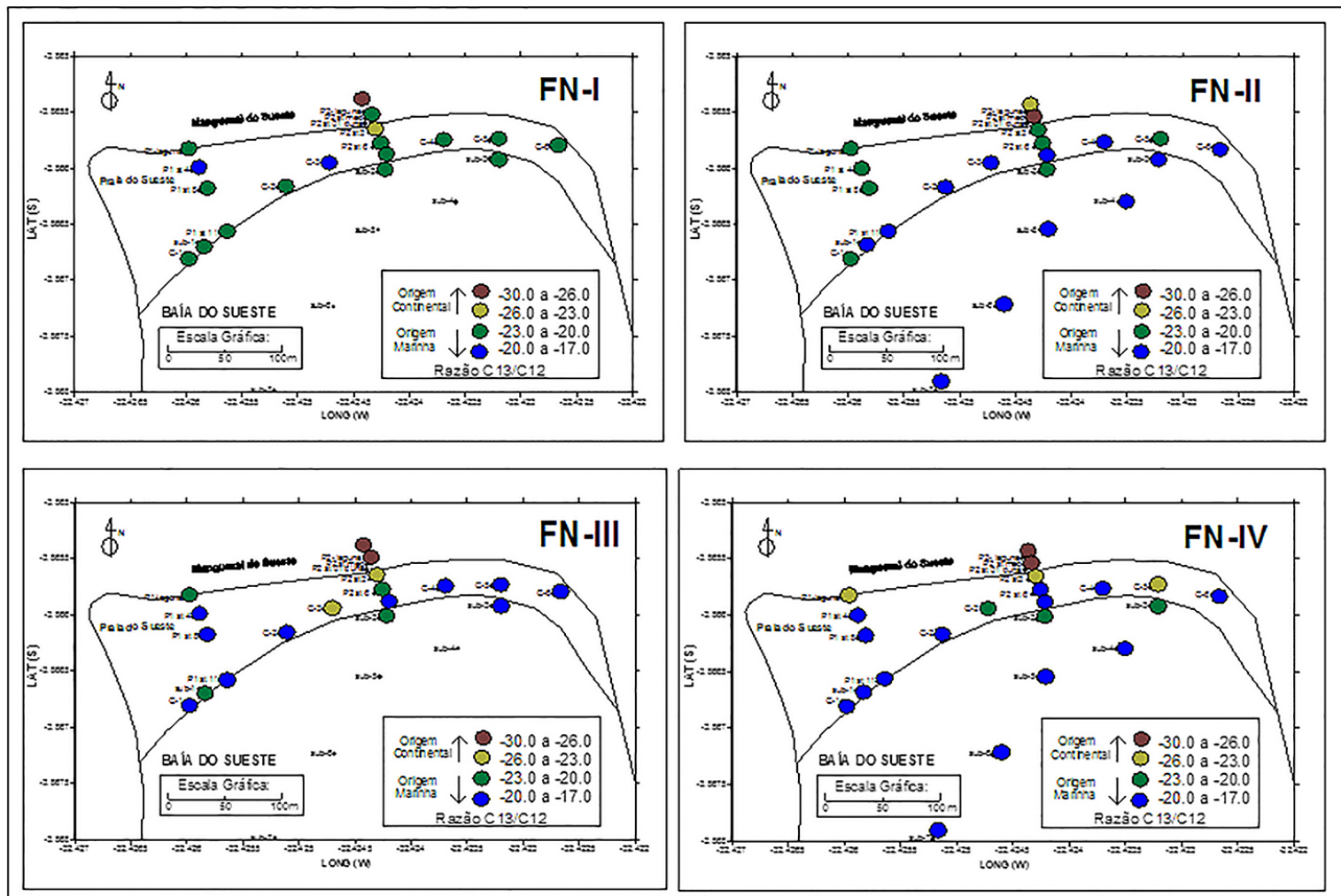

Figura 13 - Razão isotópica $\delta 13 C$ dos sedimentos das campanhas FN-I (jan/10), FN-II (abr/10), FN-III (jun/10) eFN-IV (out/10). 
A matéria orgânica mostrou ser de origem predominantemente marinha $(\mathrm{C} / \mathrm{N}<12$ e $\delta^{13} \mathrm{C}>-19 \%$ oPD), de acordo com os valores observados para a razão elementar $\mathrm{C} / \mathrm{N}$ e razão isotópica $\delta^{13} \mathrm{C}$. E confirmando os dados da fração arenosa ao apresentar as influências de materiais de origem terrígena na boca do córrego Maceió, laguna (-26\% PDB) e no lado leste da praia, devido às rochas fontes.

Para uma praia de bolso abrigada por bancos de corais (como no caso da baía de Kailua, Oahu, Havaí), um padrão de transporte simples é o fator causador destas variações morfológicas observadas. As quais dependem, em parte, da topografia dos bancos de corais adjacentes (Norcross et al., 2002). Os processos morfodinâmicos para as praias setentrionais da ilha (Sancho, Cacimba do Padre, Boldró e Conceição) são estreitamente relacionados à geomorfologia local. E, assim, como no sistema praial do Sueste, a praia do Boldró que é protegida por formações recifais, e a praia do Sancho por promontórios, apresentam menor mobilidade e menos variações no balanço sedimentar que as praias mais expostas como Conceição e Cacimba do Padre. O que estaria certamente atrelado às suas respectivas morfologias (Manso et al., 2011).

A dinâmica de correntes de deriva litorânea induzida pela forma da baía gera um transporte de sedimentos da área da estação C-4 para o oeste (Figura 14), como indicado pela distribuição dos sedimentos e morfologia da praia (2 vezes maior no lado W) (Barcellos et al., 2011). Por outro lado, a porção leste exibe sedimentação arenosa bem selecionada (estações C-5 e C-6) derivada de uma fraca corrente de deriva litorânea na direção oposta, de oeste para leste. A estação sub-5 possui maior presença de fragmentos de rochas devido à hidrodinâmica local da porção E da baía, cujo processo de refração de ondas forma um giro nas correntes que deposita sedimentos terrígenos oriundos do Morro do Madeira na área.

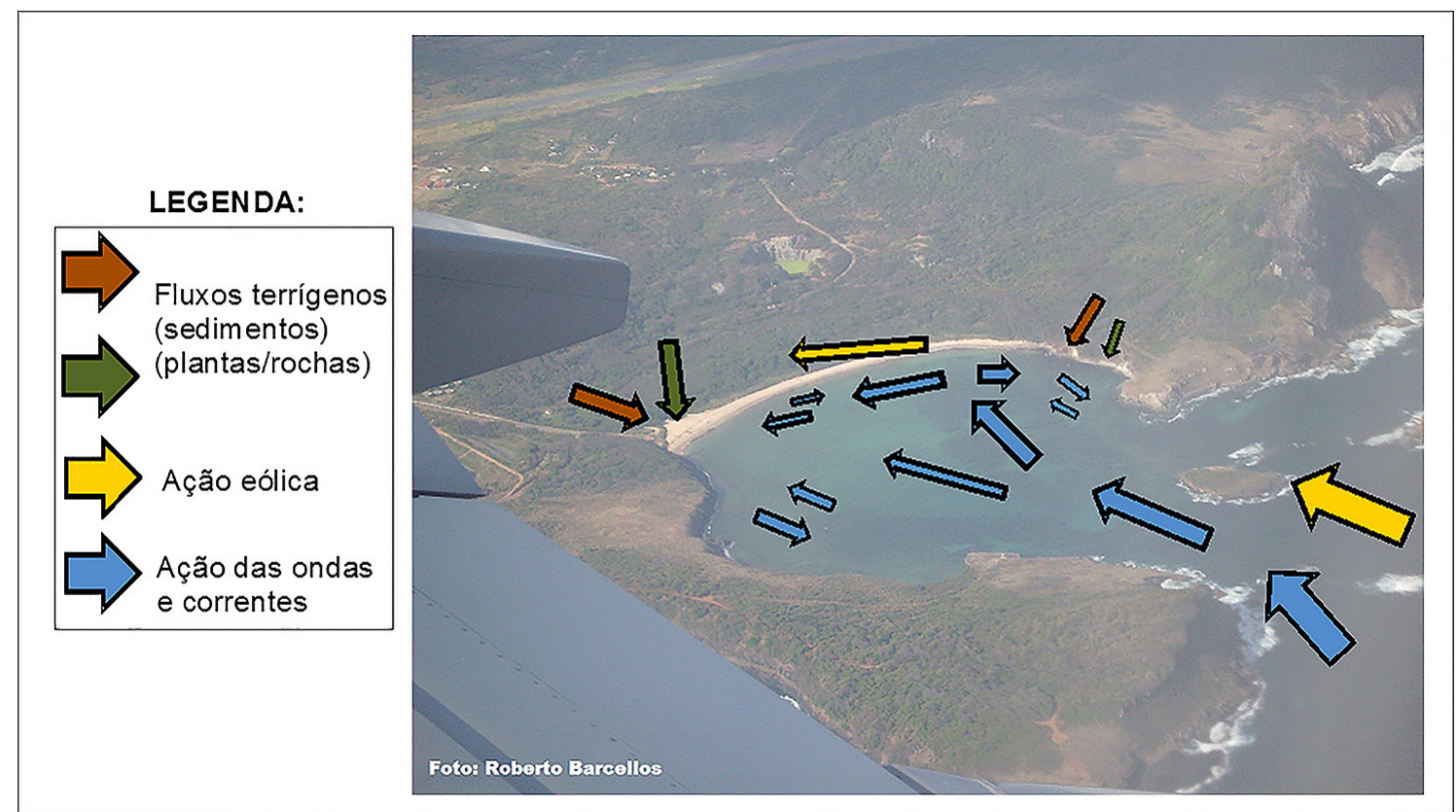

Figura 14 - Síntese da circulação e aportes locais com base nos parâmetros sedimentares analisados (Barcellos et al., 2016) (Foto: Roberto Barcellos em 14/10/2010). 


\section{CONCLUSÕES}

Apesar da homogeneidade de areias finas bioclásticas moderadamente selecionadas e matéria orgânica de origem marinha, este estudo mostra espaciais e temporais entre os sedimentos da porção oeste e leste da praia, bem como em cada compartimento do sistema praial do Sueste (laguna-mangue/duna/praia/baía).

A Baía de Sueste possui influência predominantemente marinha, o que é indicado pelos valores predominantes do índice B.M. $(0,80-0,85)$, o que é esperado para uma ilha oceânica cujos sedimentos são essencialmente bioclásticos. Apresenta, entretanto, subambientes em que ocorre alguma sedimentação terrígena, como na desembocadura do riacho Maceió, sistema lagunar e junto aos costões $\mathrm{E}$ e $\mathrm{W}$ da praia.

Uma conjunção de fatores cria as condições para este comportamento observado na morfologia da praia Sueste e sua distribuição sedimentar decorrente. Esta distribuição está diretamente relacionada à presença de fontes de sedimentos terrígenos no lado oeste e devido à ação das ondas nas rochas de origem vulcânica adjacentes, além do aporte sazonal de sedimentos do córrego Maceió. A maior exposição do lado ocidental da praia do Sueste à ação das ondas e ventos predominantes, paralelemente somado a um processo de convergência de correntes induzido pela refração e difração das ondulações de SW/S/ SE/E na entrada da baía Sueste, também contribuem para o padrão espacial de distribuição e composição de sedimentos, material orgânico e morfologia da praia que apresentou sazonalmente um déficit de sedimentos.

Por fim, espera-se que este artigo venha a contribuir com o conhecimento dos processos morfos-sedimentares e geoquímica espaço-temporais de ambientes sedimentares de costas abrigadas de ilhas oceânicas tropicais.

Agradecimentos - Os autores expressam seus agradecimentos ao CNPq pelo suporte financeiro para realização deste trabalho, parte integrante do projeto (proc. $N^{\circ}$ 577369/2008-3): "Diagnóstico ambiental do manguezal do Sueste, Arquipélago de Fernando de Noronha/PE".

\section{REFERÊNCIAS}

Almeida, F.F.M. Ilhas oceânicas brasileiras e suas relações com a tectônica atlântica. Terrae Didatica, v. 2, n. 1, p. 3-18, 2006.

Barcellos, R.L. Processo Sedimentar atual e a Distribuição da Matéria Orgânica Sedimentar (C, N e S) de São Sebastião (SP) e Plataforma Continental adjacente. Dissertação de Mestrado, IOUSP, São Paulo. 187, 2000.

Barcellos, R.L. \& Furtado, V.V. Caracterização dos componentes da fração arenosa $(0,500$ mm/0,250 mm) no Canal de São Sebastião. Pesquisas em Geociências, v. 28, n. 2, p. 35-51, 2001.

Barcellos, R.L.; Coelho Jr., C.; Lins, S.R.; Silva, M.S.; Camargo, P.B. \& Travassos, P.E. Island beaches morphological and sedimentary short term variations the case of SE Fernando de Noronha Island, South Atlantic, Brazil. Rev. Gestão Cost. Integr., v. 11, n. 4, p. 471-478, 2011.

Barcellos, R.L.; Lins, S.R.\& Coelho Jr., C. Sedimentação e Geoquímica Costeira em uma Ilha Oceânica Brasileira. 1. ed. Saarbrücken, Deutschland: NEA - Edições, v. 1. 80p., 2016.

Barcellos, R.L.; Lins, S.R.; Coelho Jr., C. \& Travassos, P.E. The coastal plain and seafloor mapping of an oceanic island sheltered coast/the case of Sueste bay, Fernando de Noronha, South Atlantic, Brazil. In: Proceeedings of $12^{\circ}$ GEOHAB. Roma, 2013. 
DHN. Carta Náutica de Fernando de Noronha. No 52. MM, Rio de Janeiro, 2009.

Fairbridge, R. The Estuary: Its Definition and Geodynamic Cycle. Chemistry and biogeochemistry of Estuaries, 1, 1980.

Flemming, B.W. A revised textural classification of gravel-free muddy sediments on the basis of ternary diagrams. Cont. Shelf Res., v. 20, n. 10, p. 1125-1137, 2000.

Hedges, J.I. \& Stern, J.H. Carbon and Nitrogen determination in carbonate-containing solids. Limnol. Oceanogr., v. 29, p. 45-57, 1984.

Hoflich, O. Climate of the South Atlantic Ocean. In: Van Loon H. (ed) Climates of the oceans. P. 1-192. Elsevier, 1984.

Hubert, J.F. Analysis of Heavy-mineral Assemblages. In: Carver, R. E. (ed.). Procedures in Sedimentary Petrology. New York, Wiley-Interscience. p. 453-478, 1971.

Johnson, H.D. \& Baldwin, C.T. Shallow clastic seas.In: Reading, W. (ed.) Sedimentary environments: processes, facies and stratigraphy, v. 3, p. 232-280, 1996.

Kench, P.S. Contemporary sedimentation in the Cocos (Keeling) Islands, Indian Ocean: interpretation using settling velocity analysis. Sedimentary Geology, v. 114, n. 1-4, p.109-130, 1997. http:/ / www.sciencedirect.com/science/article/ pii/S0037073897000821

Kikuchi, R.K.P. \& Leão, Z.M.A.N. Rocas (Southwestern Equatorial Atlantic, Brazil: an atoll built primarly by coralline algae. In: Lessios, H. \& Macintyre, I. (eds), Proocedings of the International Coral Reef Symposium, 1:731-736. Smithsonian Tropical Research Institute, Panamá, 1997.

Kikuchi, R.K.P. Atol das Rocas, AtlânticoSul Equatorial occidental, Brasil. In: Schobbenhaus, C.; Campos, D.A.; Queiroz, E.T; Winge, M \& Berbert-Born, M. (eds.), Sítios Geológicos e paleontológicos do Brasil, 1999.

Larssoneur, C.; Bouysse, P. \& Aufret, J.P. The Superficial Sediments of the English Channel and its Western Approach. Sedimentology, v. 29, n. 6, p. 851-864, 1982.

Lins, S.R.R.M. Variações morfodinâmicas, geoquímicas sazonais e análise dos componentes da fração arenosa no sistema praial do Sueste, Fernando de Noronha-PE. Monografia de graduação, DOCEAN-UFPE, Recife, 74p, 2016.

Mahiques, M.M. Considerações sobre os Sedimentos de Superfície de Fundo da Baía da Ilha Grande, Estado do Rio de Janeiro. Dissertação de Mestrado. Instituto Oceanográfico - USP, São Paulo, 139 p, 1987.

Mahiques, M.M. Variações temporais na sedimentação quartenária dos embaiamentos da região de Ubatuba, Estado de São Paulo. Dissertação de Mestrado. Universidade de São Paulo, 1992.

Mahiques, M.M.; Tessler, M.G. \& Furtado, V.V. Characterization of Energy Gradient in Enclosed Bays of Ubatuba Region, South-Eastern Brazil. Est. Coast. Shelf Sci., v. 47, p. 431-446, 1998.

Manso, V.A.V.; Menor, E.A.; Valença, L.M.M.; Neumann, V.H.M.L.; Pereira, N.S; Junior, C.F.A.S. \& Silva, E.R.M. Morfodinâmica de praias setentrionais da Ilha de Fernando de Noronha. Rev. Gest. Cost. Integr., v. 11, n. 3, p. 327-339, 2011.

Norcross, Z.M.; Fletcher, C.H. \& Merrifield, M. Annual and interannual changes on a reef-fringed pocket beach: Kailua Bay, Hawaii. Mar. Geol., v. 190, n. 3-4, p. 553-580, 2002. http:/ / www.sciencedirect.com/science/article/pii/S0025322702004804 
Pejrup, M. The triangular diagram used for classification of estuarine sediments: a new approach. Tide-influenced sedimentary environments and facies. Reidel, Dordrecht, p. 289-300, 1988.

Pereira, N.S.; Manso, V.A.V.; Silva, A.M.C. \& Silva, M.B. Mapeamento geomorfológico e morfodinâmica do Atol das Rocas, Atlântico Sul. Ver. Gest. Cost. Integr., v.10, n.3, p. 331-345, 2010.

Pessenda, L.C.R.; Gouveia, S.E.M.; Ledru, M.P.; Aravena, R.; Menor, E.A. \& Branco, F.R. Interdisciplinary paleovegetation study in the Fernando de Noronha Island (Pernambuco State), northeastern Brazil. An. Acad. Bras. Ciên., v. 80, p. 677-691, 2008.

Pettijohn, F.J. Sedimentary Rocks. Harper and Row Publishers. New York, 628p, 1975.

Rooney, J. J. B. \& Fletcher, C. H. Shoreline change and Pacific climatic oscillations in Kihey, Maui, Hawaii. Journ. Coast. Res., 21(3):535-547. ISSN 0749-0208, 2004.

Shepard, F.P. Nomenclature Based on Sand-Silt-Clay Ratios. Jour. of Sedim. Petrology, v. 24, n. 3, p. 151-158, 1954.

Shepard, F.P. \& Moore, D.G. Sedimentary Environments Differentiated by Coarse Fraction Analysis. Bull. An. Assoc. Petrol. Geol., v. 38, n. 8, p. 1792-1802, 1954.

Suguio, K. Introdução à Sedimentologia. São Paulo, Ed. Ed. Blücher/EDUSP. 317p, 1973.

Teixeira, W.; Cordani, U.G.; Menor, E.A.; Teixeira, M.G \& Linsker, R. Arquipélago de Fernando de Noronha o paraíso do vulcão. Terra Virgem Editora, São Paulo, Brasil, 167p, 2003. 


\section{APÊNDICE A}

\section{Tabelas com as informações das análises granulométricas e geoquímicas realizadas}

Localização, granulometria, parâmetros estatísticos de Folk \& Ward (1957), classificação do diagrama triangular de Shepard (1954), teores de carbonato biodetrítico, matéria orgânica total, $\mathrm{C}$ e $\mathrm{N}$ elementares, razões $\mathrm{C} / \mathrm{N}$ e dos isótopos estáveis de carbono $\left(\delta^{13} \mathrm{C}\right)$ e nitrogênio $\left({ }^{15} \mathrm{~N}\right)$ das amostras da campanha FN-I de Janeiro de 2010.

\begin{tabular}{|c|c|c|c|c|c|c|c|c|c|c|c|c|c|c|c|c|}
\hline Estação & $\begin{array}{c}\text { Latitude } \\
\text { (S) }\end{array}$ & $\begin{array}{c}\text { Longitude } \\
\text { (W) }\end{array}$ & \begin{tabular}{c|c|}
$\%$ & \\
$\mathrm{CaCO} 3$
\end{tabular} & $\begin{array}{c}\text { MO } \\
\text { total } \%\end{array}$ & $\begin{array}{c}\% \\
\text { Gran }\end{array}$ & $\begin{array}{c}\% \\
\text { Areia }\end{array}$ & \begin{tabular}{|c|}
$\%$ \\
Silte
\end{tabular} & \begin{tabular}{c|}
$\%$ \\
Argila \\
\end{tabular} & $\begin{array}{c}\text { Shepard } \\
\text { (1954) }\end{array}$ & $\begin{array}{c}\text { D. } \\
\text { Medio }\end{array}$ & Gr.Sel. & $\% \mathrm{C}$ & $\% \mathbf{N}$ & $\begin{array}{l}\text { Rz. } \\
\text { C/N }\end{array}$ & $\partial^{13} \mathrm{C}$ & $\partial^{15} \mathbf{N}$ \\
\hline $\begin{array}{l}\text { P1- st } \\
\text { laguna }\end{array}$ & $3^{\circ} 51,951^{\prime}$ & $32^{\circ} 25,561^{\prime}$ & 92,7 & 5,6 & 0,35 & 99,10 & 0,42 & 0,14 & Areia & 2,35 & 0,45 & 4,50 & 0,44 & 10,3 & $-21,7$ & 3,7 \\
\hline P1-st 4 & $3^{\circ} 51,961^{\prime}$ & $32^{\circ} 25,557^{\prime}$ & 93,5 & 1,5 & 0,00 & 99,90 & 0,10 & 0,00 & Areia & 2,43 & 0,40 & 2,29 & 0,26 & 8,8 & $-19,5$ & 4,4 \\
\hline P1-st 8 & $3^{\circ} 51,972^{\prime}$ & $32^{\circ} 25,553^{\prime}$ & 91,4 & 1,0 & 0,00 & 99,67 & 0,27 & 0,07 & Areia & 2,22 & 0,45 & 0,53 & 0,04 & 12,6 & $-21,2$ & 6,9 \\
\hline P1-st11 & $3^{\circ} 51,995^{\prime}$ & $32^{\circ} 25,542^{\prime}$ & 95,6 & 2,1 & 0,00 & 99,49 & 0,40 & 0,10 & Areia & 2,36 & 0,46 & 1,21 & 0,10 & 12,1 & $-21,7$ & 5,2 \\
\hline $\begin{array}{l}\text { P2- st } \\
\text { laguna }\end{array}$ & $3^{\circ} 51,930^{\prime}$ & $32^{\circ} 25,465^{\prime}$ & 73,8 & 2,0 & 0,04 & 87,31 & 10,9 & 1,75 & Areia & 2,76 & 1,08 & 4,09 & 0,29 & 13,9 & $-28,2$ & 8,0 \\
\hline P2- st med & $3^{\circ} 51,933^{\prime}$ & $32^{\circ} 25,464^{\prime}$ & 95,2 & 1,3 & 0.00 & 99,66 & 0,27 & 0.07 & Areia & 2,49 & 0,48 & 1,67 & 0,17 & 10,0 & $-20,4$ & 4,9 \\
\hline $\begin{array}{l}\text { P2- st } 1 \\
\text { duna }\end{array}$ & $3^{\circ} 51,936^{\prime}$ & $32^{\circ} 25,464^{\prime}$ & 93,3 & 1,5 & 0,38 & 98,86 & 0,63 & 0,13 & Areia & 2,44 & 0,50 & 10,83 & 0,90 & 12,0 & $-24,8$ & 5,2 \\
\hline P2- st3 & $3^{\circ} 51,941^{\prime}$ & $32^{\circ} 25,462^{\prime}$ & 95,4 & 1,6 & 0,00 & 99,60 & 0,33 & 0,07 & Areia & 2,39 & 0,46 & 1,01 & 0,09 & 11,6 & $-21,1$ & 5,8 \\
\hline P2-st 6 & $3^{\circ} 51,949^{\prime}$ & $32^{\circ} 25,460^{\prime}$ & 95,5 & 2,9 & 0,51 & 96,56 & 2,39 & 0,55 & Areia & 2,19 & 0,88 & 2,83 & 0,27 & 10,3 & $-20,7$ & 4,1 \\
\hline C-1 & $3^{\circ} 52,006^{\prime}$ & $32^{\circ} 25,561^{\prime}$ & 95,6 & 2,1 & 0,00 & 100,00 & 0,00 & 0,00 & Areia & 2,22 & 0,44 & 0,86 & 0,07 & 12,6 & $-21,7$ & 5,4 \\
\hline$C-2$ & $3^{\circ} 51,970^{\prime}$ & $32^{\circ} 25,511^{\prime}$ & 95,6 & 2,4 & 0,00 & 99,56 & 0,37 & 0,07 & Areia & 2,45 & 0,53 & 1,49 & 0,14 & 10,9 & $-20,5$ & 5,1 \\
\hline C-3 & $3^{\circ} 51,957^{\prime}$ & $32^{\circ} 25,487^{\prime}$ & 96,0 & 2,9 & 0,00 & 100,00 & 0,00 & 0,00 & Areia & 2,26 & 0,42 & 2,58 & 0,28 & 9,1 & $-19,6$ & 4,2 \\
\hline$C-4$ & $3^{\circ} 51,946^{\prime}$ & $32^{\circ} 25,426^{\prime}$ & 95,9 & 3,8 & 0,24 & 99,09 & 0,57 & 0,10 & Areia & 2,29 & 0,65 & 0,51 & 0,04 & 14,2 & $-22,2$ & 6,5 \\
\hline$C-5$ & $3^{\circ} 51,945^{\prime}$ & $32^{\circ} 25,397^{\prime}$ & 95,3 & 3,4 & 0,00 & 99,42 & 0,48 & 0,10 & Areia & 2,49 & 0,42 & 2,23 & 0,22 & 9,9 & $-20,3$ & 4,3 \\
\hline$C-6$ & $3^{\circ} 51,949^{\prime}$ & $32^{\circ} 25,364^{\prime}$ & 95,0 & 3,2 & 0,03 & 99,90 & 0,07 & 0,00 & Areia & 2,65 & 0,36 & 1,66 & 0,16 & 10,4 & $-20,4$ & 4,9 \\
\hline sub-1 & $3^{\circ} 52,000^{\prime}$ & $32^{\circ} 25,554^{\prime}$ & 93,0 & 2,0 & 0,57 & 98,82 & 0,51 & 0,10 & Areia & 2,18 & 0,61 & 0,58 & 0,05 & 12,5 & $-21,5$ & 5,8 \\
\hline sub-2 & $3^{\circ} 51,962^{\prime}$ & $32^{\circ} 25,457^{\prime}$ & 94,3 & 2,1 & 0,24 & 99,39 & 0,30 & 0,07 & Areia & 2,16 & 0,87 & 1,34 & 0,13 & 10,5 & $-20,2$ & 5,0 \\
\hline sub-3 & $3^{\circ} 51,955^{\prime}$ & $32^{\circ} 25,397^{\prime}$ & 94,7 & 1,9 & 0,37 & 98,96 & 0,54 & 0,13 & Areia & 2,15 & 0,87 & 1,28 & 0,11 & 11,2 & $-21,0$ & 4,7 \\
\hline
\end{tabular}


Localização, granulometria, parâmetros estatísticos de Folk \& Ward (1957), classificação do diagrama triangular de Shepard (1954), teores de carbonato biodetrítico, matéria orgânica total, $\mathrm{C}$ e $\mathrm{N}$ elementares, razões $\mathrm{C} / \mathrm{N}$ e dos isótopos estáveis de carbono $\left(\delta^{13} \mathrm{C}\right)$ e nitrogênio $\left(\delta^{15} \mathrm{~N}\right)$ das amostras da campanha FN-II de Abril de 2010.

\begin{tabular}{|c|c|c|c|c|c|c|c|c|c|c|c|c|c|c|c|c|}
\hline Estação & $\begin{array}{c}\text { Latitude } \\
\text { (S) }\end{array}$ & $\begin{array}{l}\text { Longitude } \\
\text { (W) }\end{array}$ & $\begin{array}{c}\% \\
\mathrm{CaCO} 3\end{array}$ & $\begin{array}{c}\text { MO } \\
\text { total } \%\end{array}$ & $\begin{array}{c}\% \\
\text { Gran }\end{array}$ & $\begin{array}{c}\% \\
\text { Areia }\end{array}$ & $\begin{array}{c}\% \\
\text { Silte }\end{array}$ & $\begin{array}{c}\% \\
\text { Argila }\end{array}$ & $\begin{array}{c}\text { Shepard } \\
\text { (1954) }\end{array}$ & Estação & Gr.Sel. & $\% \mathrm{C}$ & $\% \mathbf{N}$ & $\begin{array}{l}\text { Rz. } \\
\text { C/N }\end{array}$ & $\partial^{13} \mathrm{C}$ & $\partial^{15} \mathrm{~N}$ \\
\hline $\begin{array}{l}\text { P1- st } \\
\text { laguna }\end{array}$ & $3^{\circ} 51,951^{\prime}$ & $32^{\circ} 25,561^{\prime}$ & 91,0 & 0,8 & 0,17 & 99,77 & 0,07 & 0,00 & Areia & 2,10 & 0,53 & 0,63 & 0,05 & 13,3 & $-20,5$ & 6,6 \\
\hline P1-st 4 & $51,961^{\prime}$ & $32^{\circ} 25,557^{\prime}$ & 91,8 & 0,4 & 0,00 & 100,0 & 0,00 & 0,00 & Areia & 2,26 & 0,47 & 0,39 & 0,03 & 11,8 & $-20,1$ & 6,6 \\
\hline P1-st 8 & $3^{\circ} 51,972^{\prime}$ & $32^{\circ} 25,553^{\prime}$ & 89,9 & 0,6 & 0,00 & 100,0 & 0,00 & 0,00 & Areia & 2,05 & 0,60 & 0,38 & 0,03 & 13,1 & $-20,3$ & 6,1 \\
\hline P1-st 11 & $3^{\circ} 51,995^{\prime}$ & $32^{\circ} 25,542^{\prime}$ & 94,3 & 2,1 & 0,20 & 99,80 & 0,00 & 0,00 & Areia & 2,53 & 0,43 & 0,71 & 0,07 & 10,0 & $-19,1$ & 5,1 \\
\hline $\begin{array}{l}\text { P2- st } \\
\text { laguna }\end{array}$ & '51,930' & $32^{\circ} 25,465^{\prime}$ & 75,7 & 11,5 & 3,50 & 84,11 & 9,91 & 2,48 & Areia & 2,61 & 1,35 & 18,15 & 1,03 & 17,6 & $-24,9$ & 6,6 \\
\hline $2-s t$ & $3^{\circ} 51,933^{\prime}$ & $32^{\circ} 25,464^{\prime}$ & 92,0 & 2,1 & 0,40 & 99,24 & 0,27 & 0,10 & Areia & 2,43 & 0,45 & 8,88 & 0,63 & 14,0 & $-27,4$ & 6,3 \\
\hline $\begin{array}{l}\text { P2-st } 1 \\
\text { duna }\end{array}$ & $51,936^{\prime}$ & $32^{\circ} 25,464^{\prime}$ & 92,0 & 1,5 & 0,23 & 99,40 & 0,27 & 0,10 & Areia & 2,42 & 0,46 & 9,67 & 0,77 & 12,6 & $x$ & 6,7 \\
\hline P2- st3 & '51,941' & $32^{\circ} 25,462^{\prime}$ & 94,2 & 0,5 & 0,20 & 99,80 & 0,00 & 0,00 & & 2,29 & 0,51 & 0,94 & 0,09 & 10,1 & $-20,4$ & 5,1 \\
\hline P2- st 6 & $3^{\circ} 51,949^{\prime}$ & $32^{\circ} 25,460^{\prime}$ & 95,6 & 3,9 & 0,03 & 99,83 & 0,13 & 0,00 & Areia & 2,22 & 0,59 & 2,01 & 0,24 & 8,4 & $-18,3$ & 3,4 \\
\hline C-1 & $3^{\circ} 52,006^{\prime}$ & $32^{\circ} 25,561^{\prime}$ & 94,9 & 2,4 & 0,20 & 99,80 & 0,00 & 0,00 & Areia & 2,12 & 0,56 & 0,65 & 0,06 & 10,1 & $-20,2$ & 4,8 \\
\hline C-2 & '51,970' & $32^{\circ} 25,511^{\prime}$ & 94,8 & 3,3 & 0,27 & 99,73 & 0,00 & 0,00 & Areia & 2,32 & 0,59 & 0,66 & 0,06 & 10,2 & $-19,8$ & 5,6 \\
\hline C-3 & $3^{\circ} 51,957^{\prime}$ & $32^{\circ} 25,487^{\prime}$ & 96,1 & 2,5 & 0,17 & 99,80 & 0,30 & 0,00 & Areia & 2,33 & 0,58 & 1,03 & 0,12 & 8,8 & $-19,5$ & 4,5 \\
\hline C- 4 & $3^{\circ} 51,946^{\prime}$ & $32^{\circ} 25,426^{\prime}$ & 95,2 & 3,7 & 0,07 & 99,93 & 0,00 & 0,00 & Areia & 2,39 & 0,52 & 1,73 & 0,20 & 8,6 & $-19,1$ & 4,1 \\
\hline C-5 & '51,945' & $32^{\circ} 25,397^{\prime}$ & 97,1 & 3,4 & 0,20 & 99,73 & 0,07 & 0,00 & Areia & 2,52 & 0,47 & 1,06 & 0,12 & 9,1 & $-20,1$ & 3,9 \\
\hline C-6 & $3^{\circ} 51,9^{\prime}$ & $32^{\circ} 25,364^{\prime}$ & 94,6 & 3,2 & 0,27 & 99,73 & 0,00 & 0,00 & Areia & 2,53 & 0,42 & 1,17 & 0,19 & 6,2 & $-19,6$ & 4,7 \\
\hline sub-1 & $3^{\circ} 52,000^{\prime}$ & $32^{\circ} 25,554^{\prime}$ & 90,1 & 2,2 & 0,63 & 99,37 & 0,00 & 0,00 & Areia & 2,29 & 0,56 & 0,43 & 0,05 & 7,8 & $-19,1$ & 4,8 \\
\hline sub-2 & $3^{\circ} 51,962^{\prime}$ & $32^{\circ} 25,457^{\prime}$ & 95,2 & 2,8 & 0,30 & 99,64 & 0,07 & 0,00 & Areia & 2,16 & 0,68 & 1,16 & 0,15 & 7,6 & $-17,4$ & 3,4 \\
\hline sub-3 & $3^{\circ} 51,955^{\prime}$ & $32^{\circ} 25,397^{\prime}$ & 87,1 & 3,0 & 0,98 & 99,02 & 0,00 & 0,00 & Areia & 1,68 & 0,83 & 0,75 & 0,08 & 9,0 & $-17,7$ & 5,5 \\
\hline sub-4 & $3^{\circ} 51,931^{\prime}$ & $32^{\circ} 25,464^{\prime}$ & 89,5 & 2,2 & 0,91 & 99,09 & 0,00 & 0,00 & Areia & 2,81 & 0,77 & 0,61 & 0,07 & 8,2 & $-17,7$ & 5,9 \\
\hline sub-5 & $3^{\circ} 51,938^{\prime}$ & $32^{\circ} 25,468^{\prime}$ & 90,5 & 2,5 & 0,00 & 97,08 & 2,92 & 0,00 & Areia & 2,81 & 1,08 & 0,73 & 0,08 & 8,6 & $-19,3$ & 4,8 \\
\hline sub-6 & $3^{\circ} 51,978^{\prime}$ & $32^{\circ} 25,415^{\prime}$ & 91,3 & 2,7 & 0,07 & 99,74 & 0,20 & 0,00 & Areia & 2,65 & 0,53 & 0,96 & 0,14 & 6,9 & $-17,9$ & 3,9 \\
\hline sub-7 & $3^{\circ} 51,993^{\prime}$ & $32^{\circ} 25,457^{\prime}$ & 91,3 & 2,3 & 0,13 & 99,87 & 0,00 & 0,00 & Areia & 2,38 & 0,43 & 0,78 & 0,10 & 8,1 & $-18,1$ & 5,4 \\
\hline
\end{tabular}


Localização, granulometria, parâmetros estatísticos de Folk \& Ward (1957), classificação do diagrama triangular de Shepard (1954), teores de carbonato biodetrítico, matéria orgânica total, $\mathrm{C}$ e $\mathrm{N}$ elementares, razões $\mathrm{C} / \mathrm{N}$ e dos isótopos estáveis de carbono $\left(\delta^{13} \mathrm{C}\right)$ e nitrogênio $\left({ }^{15} \mathrm{~N}\right)$ das amostras da campanha FN-III de Junho de 2010.

\begin{tabular}{|c|c|c|c|c|c|c|c|c|c|c|c|c|c|c|c|c|}
\hline Estação & $\begin{array}{l}\text { Latitude } \\
\text { (S) }\end{array}$ & $\begin{array}{l}\text { Longitude } \\
\text { (W) }\end{array}$ & $\begin{array}{c}\% \\
\mathrm{CaCO} 3\end{array}$ & $\begin{array}{c}\text { MO } \\
\text { total } \%\end{array}$ & $\begin{array}{c}\% \\
\text { Gran }\end{array}$ & $\begin{array}{c}\% \\
\text { Areia }\end{array}$ & $\begin{array}{c}\% \\
\text { Silte }\end{array}$ & $\begin{array}{c}\% \\
\text { Argila }\end{array}$ & $\begin{array}{c}\text { Shepard } \\
\text { (1954) }\end{array}$ & $\begin{array}{c}\text { D. } \\
\text { Medio }\end{array}$ & Gr.Sel. & $\% \mathrm{C}$ & $\% \mathrm{~N}$ & $\begin{array}{l}\text { Rz. } \\
\text { C/N }\end{array}$ & $\partial^{13} \mathrm{C}$ & $\partial^{15} \mathrm{~N}$ \\
\hline $\begin{array}{l}\text { P1- st } \\
\text { laguna }\end{array}$ & & $32^{\circ} 25,561^{\prime}$ & 91,2 & 1,33 & 0,10 & 99,56 & 0,34 & 0,00 & Areia & 2,18 & 0,49 & 0,74 & 0,07 & 9,9 & $-21,5$ & 6,9 \\
\hline P1-st 4 & $51,961^{\prime}$ & 20255571 & 92,4 & 0,45 & 0,00 & 100,00 & 0,00 & 0,00 & Areia & 2,29 & 0,38 & 0,48 & 0,05 & 9,9 & $-19,1$ & 7,4 \\
\hline P1-st 8 & $3^{\circ} 51,972^{\prime}$ & 25,553 & 89,5 & 33,90 & 0,00 & 100,00 & 0,00 & 0,00 & Areia & 2,28 & 0,46 & 0,27 & 0,03 & 9,7 & $-18,3$ & 7,2 \\
\hline P1-st 11 & $3^{\circ} 51,995^{\prime}$ & 320255421 & 91,6 & 1,60 & 007 & 99,90 & 0,03 & 0,00 & Areia & 244 & 0,39 & 0,32 & 0,03 & 9,9 & $-19,7$ & 6,9 \\
\hline & 5 & $32^{\circ} 25,465^{\prime}$ & 51,8 & 12,30 & 1,45 & 42,03 & 42,40 & 14,12 & Arenoso & 5,09 & 2,38 & 5,67 & 0,42 & 13,5 & $-27,0$ & 7,1 \\
\hline P2- st med & $3^{\circ} 51,933^{\prime}$ & $32^{\circ} 25,464^{\prime}$ & 89,9 & & 063 & 98,86 & 0,40 & 0,10 & & & & 17,50 & 0,73 & 23,9 & $-27,9$ & 6,8 \\
\hline & '51,936' & $32^{\circ} 25,464^{\prime}$ & 91,9 & 2,67 & 0,17 & 99,13 & 0,57 & 0,13 & Areia & 2,47 & 0,46 & 11,55 & 0,88 & 13,1 & $-24,1$ & 5,6 \\
\hline P2- st3 & $3^{\circ} 51,941^{\prime}$ & $5025462^{\prime}$ & 94,2 & 0,60 & 0,00 & 100,00 & 0,00 & 0,00 & Areia & 2,25 & 0,50 & 1,67 & 0,17 & 10,1 & $-21,4$ & 5,6 \\
\hline P2- st 6 & 351,949 & 20,400 & 94,1 & 2,10 & 0,00 & 99,97 & 0,03 & 0,00 & Hera & 2,00 & 0,00 & 0,83 & 0,10 & 8,4 & $-17,8$ & 5,8 \\
\hline C-1 & $3^{\circ} 52,006^{\prime}$ & $2^{\circ} 25,561^{\prime}$ & 91,0 & 1,87 & 0,27 & 99,70 & 0,03 & 0,00 & Areia & 2,26 & 0,51 & 0,46 & 0,05 & 10,1 & $-19,0$ & 6,8 \\
\hline $\mathrm{C}-2$ & $3^{\circ} 51,970^{\prime}$ & $32^{\circ} 25,511^{\prime}$ & 93,1 & 1,80 & 3,15 & 96,85 & 0,00 & 0,00 & Areia & 2,38 & , & 0,53 & 0,06 & 9,2 & $-18,9$ & 7,1 \\
\hline$C-3$ & $3^{\circ} 51,957^{\prime}$ & $32^{\circ} 25,487^{\prime}$ & 93,5 & 1,95 & 0,27 & 99,70 & 0,03 & 0,00 & Areia & 2,46 & 040 & 0,28 & 0,02 & 12,9 & $-24,5$ & 6,2 \\
\hline $\mathrm{C}-4$ & $3^{\circ} 51,946^{\prime}$ & $32^{\circ} 25,426^{\prime}$ & 94,0 & 2,55 & 0,20 & 99,77 & 0,03 & 0,00 & Areia & 2,53 & 0,44 & 1,41 & 0,17 & 8,5 & $-17,6$ & 4,9 \\
\hline C-5 & $3^{\circ} 51,945^{\prime}$ & $32^{\circ} 25,397^{\prime}$ & 95,6 & 2,85 & 0,30 & 99,70 & 0,00 & 0,00 & Areia & 2,33 & 0,59 & 1,12 & 0,13 & 8,7 & $-17,7$ & 5,0 \\
\hline$C-6$ & $3^{\circ} 51,949^{\prime}$ & $32^{\circ} 25,364^{\prime}$ & 95,1 & 2,95 & 0,00 & 99,97 & 0,03 & 0,00 & Areia & 2,47 & 0,46 & 1,35 & 0,15 & 9,1 & $-18,5$ & 5,3 \\
\hline sub-1 & $3^{\circ} 52,000^{\prime}$ & $32^{\circ} 25,554^{\prime}$ & 94,7 & 1,85 & 0,10 & 99,87 & 0,03 & 0,00 & Areia & 2,30 & 0,42 & 0,93 & 0,11 & 8,8 & $-18,5$ & 5,9 \\
\hline sub-2 & $3^{\circ} 51,962^{\prime}$ & $32^{\circ} 25,457^{\prime}$ & 91,6 & 2,20 & 0,00 & 99,97 & 0,03 & 0,00 & Areia & 2,41 & 0,45 & 0,56 & 0,05 & 12,1 & $-20,1$ & 6,4 \\
\hline sub-3 & $3^{\circ} 51,955^{\prime}$ & $32^{\circ} 25,397^{\prime}$ & 94,9 & 2,55 & 0,70 & 99,30 & 0,00 & 0,00 & Areia & 1,79 & 0,94 & 1,24 & 0,13 & 9,7 & $-19,9$ & 5,2 \\
\hline
\end{tabular}


Localização, granulometria, parâmetros estatísticos de Folk \& Ward (1957), classificação do diagrama triangular de Shepard (1954), teores de carbonato biodetrítico, matéria orgânica total, $\mathrm{C}$ e $\mathrm{N}$ elementares, razões $\mathrm{C} / \mathrm{N}$ e dos isótopos estáveis de carbono $\left(\delta^{13} \mathrm{C}\right)$ e nitrogênio $\left({ }^{15} \mathrm{~N}\right)$ das amostras da campanha FN-VI de Outubro de 2010.

\begin{tabular}{|c|c|c|c|c|c|c|c|c|c|c|c|c|c|c|c|c|}
\hline Estação & $\begin{array}{l}\text { Latitude } \\
\text { (S) }\end{array}$ & $\begin{array}{l}\text { Longitude } \\
\text { (W) }\end{array}$ & \begin{tabular}{c|}
$\%$ \\
$\mathrm{CaCO} 3$ \\
\end{tabular} & $\begin{array}{c}\text { MO } \\
\text { total } \%\end{array}$ & \begin{tabular}{|c|}
$\%$ \\
Gran
\end{tabular} & $\begin{array}{c}\% \\
\text { Areia }\end{array}$ & \begin{tabular}{|c|}
$\%$ \\
Silte \\
\end{tabular} & $\begin{array}{c}\% \\
\text { Argila }\end{array}$ & $\begin{array}{c}\text { Shepard } \\
\text { (1954) }\end{array}$ & $\begin{array}{c}\text { D. } \\
\text { Medio }\end{array}$ & Gr.Sel. & $\% \mathrm{CC}$ & $\% \mathbf{N}$ & $\begin{array}{l}\text { Rz. } \\
\text { C/N }\end{array}$ & $\partial^{13} \mathrm{C}$ & $\partial^{15} \mathbf{N}$ \\
\hline & $3^{\circ} 51,951^{\prime}$ & $32^{\circ} 25,561^{\prime}$ & 93,7 & 1,60 & 0,30 & 99,70 & 0,00 & 0,00 & Areia & 2,45 & 0,43 & 3,05 & 0,21 & 14,6 & $-25,2$ & 5,0 \\
\hline P1-st 4 & '51,961' & י & 93,3 & 1,00 & 0,00 & 100,00 & 0,00 & 0.00 & rois & 2,23 & 0,46 & ,37 & 0,04 & 10,1 & $-19,8$ & 6,6 \\
\hline P1-st 8 & ॰51,972' & 25,553 & 95,6 & 1,45 & 0,00 & 100,00 & 0,00 & 0.00 & roia & 2,68 & 0,51 & 0,77 & 0,08 & 9,9 & $-19,2$ & 5,9 \\
\hline P1-st 11 & $3^{\circ} 51,995^{\prime}$ & (2) & 94,8 & 3,80 & 0,27 & 99,73 & 0,00 & & & 25 & & 1,15 & 0,12 & 9,5 & $-19,3$ & 5,0 \\
\hline & $3^{\circ} 51,930^{\prime}$ & $32^{\circ} 25,465^{\prime}$ & 46,5 & 28,05 & 2,70 & 16,81 & 73,39 & 7,10 & Silte & 5,47 & 1,89 & 12,51 & 0,62 & 20,1 & $-28,3$ & 7,2 \\
\hline P2- st med & ${ }^{\circ} 51,933$ & 025 & 91,6 & 2,83 & 0,20 & 99,30 & 0,40 & 010 & & 2,43 & & 15,43 & 0,71 & 21,8 & $-28,0$ & 6,7 \\
\hline & '51,936' & 2025441 & 93,3 & 2,47 & 0,50 & 98,80 & 0,57 & 0,13 & & 2,45 & 0,47 & 16,56 & 1,12 & 14,8 & $-25,0$ & 4,7 \\
\hline P2- st3 & $3^{\circ} 51,941^{\prime}$ & 25,462 & 94,8 & 2,00 & 0,00 & 100,00 & 0,00 & 0,00 & & 2,53 & 0,42 & 1,11 & 0,12 & 9,2 & $-19,1$ & 5,5 \\
\hline P2- st 6 & $3^{\circ} 51,949^{\prime}$ & $25,460^{\prime}$ & 95,3 & 3,10 & 0,13 & 99,87 & 0,00 & 0,00 & ceia & 2,26 & 0,63 & 1,45 & 0,16 & 9,3 & $-18,3$ & 4,9 \\
\hline C-1 & $3^{\circ} 52,006^{\prime}$ & ${ }^{\circ} 25,561^{\prime}$ & 95,7 & 2,35 & 0,00 & 99,97 & 0,03 & 0,00 & reia & 2,23 & 0,54 & 0,97 & 0,09 & 11,1 & $-19,9$ & 5,5 \\
\hline $\mathrm{C}-2$ & $3^{\circ} 51,970^{\prime}$ & ${ }^{\circ} 25,511^{\prime}$ & 95,0 & 2,70 & 0,67 & 99,30 & 0,03 & 0,00 & Arein & 2,06 & 073 & 1,02 & 0,12 & 8,5 & $-17,8$ & 4,8 \\
\hline C-3 & $3^{\circ} 51,957^{\prime}$ & $32^{\circ} 25,487^{\prime}$ & 96,4 & 2,25 & 0,00 & 100,00 & 0,00 & 0,00 & $A$ rein & 2,37 & 046 & 0,62 & 0,06 & 10,0 & $-20,0$ & 5,6 \\
\hline$C-4$ & $3^{\circ} 51,946^{\prime}$ & $32^{\circ} 25,426^{\prime}$ & 95,9 & 3,10 & 0,33 & 99,57 & 0,10 & 0,00 & & 2,19 & 0,65 & 1,36 & 0,16 & 8,7 & $-18,7$ & 4,1 \\
\hline C-5 & $3^{\circ} 51,945^{\prime}$ & $32^{\circ} 25,397^{\prime}$ & 96,3 & 3,25 & 0,27 & 99,50 & 0,23 & 0,00 & & 2,50 & & 2,97 & 0,23 & 13,1 & $-24,7$ & 5,7 \\
\hline & $3^{\circ} 51,949^{\prime}$ & $32^{\circ} 25,364^{\prime}$ & & & 0,00 & 100,00 & مO مO & & & & & 1,38 & & 84 & $-18,5$ & 4,2 \\
\hline & $3^{\circ} 52,000^{\prime}$ & $-20,004$ & & & 0,33 & 99,67 & 0,00 & & & & & 0,76 & 0,08 & 9,1 & $-18,7$ & 5,5 \\
\hline sub-2 & $3^{\circ} 51,962^{\prime}$ & $32^{\circ} 25,457^{\prime}$ & 96,0 & 2,40 & 0,03 & 99,97 & 0,00 & 0,00 & & 1,86 & & 1,47 & 0,16 & 9,1 & $-18,9$ & 4,8 \\
\hline sub-3 & $3^{\circ} 51,955^{\prime}$ & $32^{\circ} 25,397^{\prime}$ & 95,2 & 2,60 & 0,10 & 99,84 & 0,06 & 0,00 & & 2,04 & & 1,10 & 0,11 & 10,3 & $-20,6$ & 4,8 \\
\hline sub-4 & $3^{\circ} 51,931^{\prime}$ & $32^{\circ} 25,464^{\prime}$ & 92,8 & 2,30 & 0,19 & 99,64 & 0,16 & 0,00 & & 2,71 & & 0,73 & 0,08 & 8,7 & $-19,3$ & 4,8 \\
\hline sub-5 & $3^{\circ} 51,938^{\prime}$ & $32^{\circ} 25,468^{\prime}$ & 92,3 & 2,60 & 0,00 & 99,83 & 0,17 & 0,00 & & 2,70 & & 1,03 & 0,13 & 8,0 & $-18,8$ & 4,5 \\
\hline sub-6 & $3^{\circ} 51,978^{\prime}$ & $32^{\circ} 25,415^{\prime}$ & 95,5 & 1,55 & 4,54 & 95,42 & 0,03 & 0,00 & & 1,10 & & 0,87 & 0,10 & 8,3 & $-19,4$ & 3,4 \\
\hline sub-7 & $3^{\circ} 51,993^{\prime}$ & $32^{\circ} 25,457^{\prime}$ & 91,8 & 2,15 & 1,10 & 97,73 & 0,93 & 0,23 & Areia & 2,93 & 0,65 & 0,86 & 0,10 & 9,1 & $-18,6$ & 5,6 \\
\hline
\end{tabular}


Localização, matéria orgânica total, granulometria, parâmetros estatísticos de Folk \& Ward (1957), classificação do diagrama triangular de Shepard (1954) e teores de carbonato biodetrítico da amostra da campanha FN-V de Março de 2011.

\begin{tabular}{|c|c|c|c|c|c|c|c|c|c|c|c|}
\hline Estação & $\begin{array}{l}\text { Latitude } \\
\text { (S) }\end{array}$ & $\begin{array}{l}\text { Longitude } \\
\text { (W) }\end{array}$ & $\begin{array}{c}\% \\
\mathrm{CaO} 3 \\
\end{array}$ & $\begin{array}{c}\text { MO } \\
\text { total } \%\end{array}$ & $\begin{array}{c}\% \\
\text { Gran } \\
\end{array}$ & $\%$ Areia & $\%$ Silte & $\begin{array}{c}\% \\
\text { Argila } \\
\end{array}$ & Shepard & $\begin{array}{c}\text { D. } \\
\text { Medio }\end{array}$ & Gr.Sel. \\
\hline P1- st laguna & $3^{\circ} 51,951^{\prime}$ & $32^{\circ} 25,561^{\prime}$ & 93,2 & 2,6 & 0,03 & 99,90 & 0,07 & 0,00 & Areia & 2,46 & 0,44 \\
\hline P1-st 4 & $3^{\circ} 51,961^{\prime}$ & $32^{\circ} 25,557^{\prime}$ & 93,4 & 0,7 & 0,00 & 100,00 & 0,00 & 0,00 & Areia & 2,46 & 0,43 \\
\hline P1-st 8 & $3^{\circ} 51,972^{\prime}$ & $32^{\circ} 25,553^{\prime}$ & 90,2 & 1,7 & 0,00 & 100,00 & 0,00 & 0,00 & Areia & 2,40 & 0,56 \\
\hline P1-st 11 & $3^{\circ} 51,995^{\prime}$ & $32^{\circ} 25,542^{\prime}$ & 92,7 & 2,7 & 0,30 & 99,70 & 0,00 & 0,00 & Areia & 2,26 & 0,72 \\
\hline P2- st laguna & $3^{\circ} 51,933^{\prime}$ & $32^{\circ} 25,464^{\prime}$ & 44,1 & 16,8 & 0,56 & 46,52 & 35,33 & 17,59 & $\begin{array}{l}\text { Areia } \\
\text { Síltica }\end{array}$ & 4,96 & 2,48 \\
\hline P2- st med & $3^{\circ} 51,936^{\prime}$ & $32^{\circ} 25,464^{\prime}$ & 92,0 & 2,7 & 0,60 & 99,16 & 0,23 & 0,00 & Areia & 2,43 & 0,45 \\
\hline P2- st 1 duna & $3^{\circ} 51,941^{\prime}$ & $32^{\circ} 25,462^{\prime}$ & 90,2 & 3,7 & 0,23 & 99,25 & 0,52 & 0,00 & Areia & 2,54 & 0,48 \\
\hline P2- st3 & $3^{\circ} 51,949^{\prime}$ & $32^{\circ} 25,460^{\prime}$ & 80,6 & 1,5 & 0,00 & 100,00 & 0,00 & 0,00 & Areia & 2,30 & 0,56 \\
\hline P2- st 6 & $3^{\circ} 52,006^{\prime}$ & $32^{\circ} 25,561^{\prime}$ & 90,5 & 2,2 & 0,00 & 100,00 & 0,00 & 0,00 & Areia & 2,23 & 0,70 \\
\hline C-1 & $3^{\circ} 51,970^{\prime}$ & $32^{\circ} 25,511^{\prime}$ & 94,5 & 4,00 & 0,47 & 99,53 & 0,00 & 0,00 & Areia & 2,37 & 0,60 \\
\hline C-2 & $3^{\circ} 51,957^{\prime}$ & $32^{\circ} 25,487^{\prime}$ & 92,9 & 2,30 & 0,07 & 99,93 & 0,00 & 0,00 & Areia & 2,36 & 0,62 \\
\hline $\mathrm{C}-3$ & $3^{\circ} 51,946^{\prime}$ & $32^{\circ} 25,426^{\prime}$ & 93,8 & 2,70 & 0,00 & 100,00 & 0,00 & 0,00 & Areia & 2,41 & 0,50 \\
\hline C-4 & $3^{\circ} 51,945^{\prime}$ & $32^{\circ} 25,397^{\prime}$ & 94,8 & 3,40 & 0,07 & 99,90 & 0,03 & 0,00 & Areia & 2,34 & 0,65 \\
\hline C-5 & $3^{\circ} 51,949^{\prime}$ & $32^{\circ} 25,364^{\prime}$ & 66,4 & 3,60 & 0,10 & 99,90 & 0,00 & 0,00 & Areia & 2,60 & 0,48 \\
\hline C-6 & $3^{\circ} 52,000^{\prime}$ & $32^{\circ} 25,554^{\prime}$ & 93,6 & 3,40 & 0,40 & 99,60 & 0,00 & 0,00 & Areia & 2,40 & 0,52 \\
\hline sub-1 & $3^{\circ} 51,962^{\prime}$ & $32^{\circ} 25,457^{\prime}$ & 94,0 & 3,2 & 0,00 & 100,00 & 0,00 & 0,00 & Areia & 2,23 & 0,58 \\
\hline sub-2 & $3^{\circ} 51,955^{\prime}$ & $32^{\circ} 25,397^{\prime}$ & 93,4 & 2,9 & 0,37 & 99,60 & 0,03 & 0,00 & Areia & 2,17 & 0,82 \\
\hline sub-3 & $3^{\circ} 51,931^{\prime}$ & $32^{\circ} 25,464^{\prime}$ & 94,5 & 3,3 & 0,44 & 99,53 & 0,03 & 0,00 & Areia & 1,54 & 0,91 \\
\hline sub-4 & $3^{\circ} 51,938^{\prime}$ & $32^{\circ} 25,468^{\prime}$ & 88,3 & 2,9 & 0,57 & 97,65 & 1,78 & 0,00 & Areia & 2,96 & 0,63 \\
\hline sub-5 & $3^{\circ} 51,978^{\prime}$ & $32^{\circ} 25,415^{\prime}$ & 90,4 & 3,2 & 0,00 & 99,53 & 0,47 & 0,00 & Areia & 2,69 & 0,76 \\
\hline sub-6 & $3^{\circ} 51,993^{\prime}$ & $32^{\circ} 25,457^{\prime}$ & 91,0 & 3,1 & 0,44 & 99,36 & 0,20 & 0,00 & Areia & 2,62 & 0,60 \\
\hline sub-7 & $3^{\circ} 51,993^{\prime}$ & $32^{\circ} 25,457^{\prime}$ & 80,3 & 1,8 & 0,30 & 99,70 & 0,00 & 0,00 & Areia & 1,94 & 0,53 \\
\hline
\end{tabular}


Localização, matéria orgânica total, granulometria, parâmetros estatísticos de Folk \& Ward (1957), classificação do diagrama triangular de Shepard (1954) e teores de carbonato biodetrítico da amostra da campanha FN-VI de Julho de 2011.

\begin{tabular}{|c|c|c|c|c|c|c|c|c|c|c|c|}
\hline Estação & Latitude (S) & \begin{tabular}{|c|} 
Longitude \\
(W)
\end{tabular} & $\begin{array}{c}\% \\
\mathrm{CaC}) 3 \\
\end{array}$ & $\begin{array}{c}\text { MO } \\
\text { total } \% \\
\end{array}$ & $\begin{array}{c}\% \\
\text { Gran } \\
\end{array}$ & $\begin{array}{c}\% \\
\text { Areia } \\
\end{array}$ & $\%$ Silte & $\begin{array}{c}\% \\
\text { Argila } \\
\end{array}$ & Shepard & $\begin{array}{c}\text { D. } \\
\text { Medio }\end{array}$ & Gr.Sel. \\
\hline P1- st laguna & $3^{\circ} 51,951^{\prime}$ & $32^{\circ} 25,561^{\prime}$ & 92,4 & 1,60 & 0,07 & 99,83 & 0,10 & 0,00 & Areia & 2,49 & 0,44 \\
\hline P1-st 4 & $3^{\circ} 51,961^{\prime}$ & $32^{\circ} 25,557^{\prime}$ & 89,0 & 1,00 & 0,00 & 100,00 & 0,00 & 0,00 & Areia & 2,43 & 0,42 \\
\hline P1-st 8 & $3^{\circ} 51,972^{\prime}$ & $32^{\circ} 25,553^{\prime}$ & 86,4 & 1,10 & 0,00 & 100,00 & 0,00 & 0,00 & & 2,46 & 0,44 \\
\hline P1-st 11 & $3^{\circ} 51,995^{\prime}$ & $32^{\circ} 25,542^{\prime}$ & 88,3 & 1,70 & 0,00 & 100,00 & 0,00 & 0,00 & & 2,33 & 0,48 \\
\hline P2- st laguna & $3^{\circ} 51,933^{\prime}$ & $32^{\circ} 25,464^{\prime}$ & 41,9 & 16,00 & 3,28 & 30,95 & 39,23 & 26,54 & $\begin{array}{c}\text { Silte } \\
\text { Argilo- } \\
\text { arenoso }\end{array}$ & 5,64 & 2,81 \\
\hline P2- st med & $3^{\circ} 51,936^{\prime}$ & $32^{\circ} 25,464^{\prime}$ & 91,1 & 4,50 & 0,10 & 99,36 & 0,53 & 0,00 & Areia & 2,34 & 0,46 \\
\hline P2- st 1 duna & $3^{\circ} 51,941^{\prime}$ & $32^{\circ} 25,462^{\prime}$ & 89,7 & 5,70 & 0,64 & 98,83 & 0,54 & 0,00 & Areia & 2,41 & 0,49 \\
\hline P2- st3 & $3^{\circ} 51,949^{\prime}$ & $32^{\circ} 25,460^{\prime}$ & 93,9 & 0,30 & 0,00 & 100,00 & 0,00 & 0,00 & Areia & 2,27 & 0,55 \\
\hline P2-st 6 & $3^{\circ} 52,006^{\prime}$ & $32^{\circ} 25,561^{\prime}$ & 95,0 & 2,80 & 0,00 & 100,00 & 0,00 & 0,00 & Are & 2,29 & 0,65 \\
\hline C-1 & $3^{\circ} 51,970^{\prime}$ & $32^{\circ} 25,511^{\prime}$ & 84,1 & 0,80 & 0,00 & 100,00 & 0,00 & 0,00 & Areia & 2,40 & 0,47 \\
\hline $\mathrm{C}-2$ & $3^{\circ} 51,957^{\prime}$ & $32^{\circ} 25,487^{\prime}$ & 93,9 & 2,00 & 0,44 & 99,56 & 0,00 & 0,00 & Areia & 2,20 & 0,54 \\
\hline$C-3$ & $3^{\circ} 51,946^{\prime}$ & $32^{\circ} 25,426^{\prime}$ & 94,4 & 2,40 & 0,07 & 99,93 & 0,00 & 0,00 & Areia & 2,39 & 0,59 \\
\hline C-4 & $3^{\circ} 51,945^{\prime}$ & $32^{\circ} 25,397^{\prime}$ & 95,2 & 4,10 & 0,07 & 99,90 & 0,03 & 0,00 & Are & 2,12 & 0,63 \\
\hline C-5 & $3^{\circ} 51,949^{\prime}$ & $32^{\circ} 25,364^{\prime}$ & 94,8 & 2,90 & 0,03 & 99,97 & 0,00 & 0,00 & Areia & 2,38 & 0,54 \\
\hline C-6 & $3^{\circ} 52,000^{\prime}$ & $32^{\circ} 25,554^{\prime}$ & 95,2 & 3,50 & 0,00 & 100,00 & 0,00 & 0,00 & Areia & 2,15 & 0,66 \\
\hline sub-1 & $3^{\circ} 51,962^{\prime}$ & $32^{\circ} 25,457^{\prime}$ & 93,1 & 1,40 & 0,00 & 100,00 & 0,00 & 0,00 & Areia & 2,43 & 0,44 \\
\hline sub-2 & $3^{\circ} 51,955^{\prime}$ & $32^{\circ} 25,397^{\prime}$ & 94,9 & 2,30 & 0,20 & 99,77 & 0,03 & 0,00 & Areia & 1,94 & 0,77 \\
\hline sub-3 & $3^{\circ} 51,931^{\prime}$ & $32^{\circ} 25,464^{\prime}$ & 94,4 & 3,00 & 0,07 & 99,87 & 0,07 & 0,00 & Areia & 2,10 & 0,87 \\
\hline sub-4 & $3^{\circ} 51,938^{\prime}$ & $32^{\circ} 25,468^{\prime}$ & 94,5 & 2,20 & 6,56 & 93,41 & 0,03 & 0,00 & Areia & 0,98 & 1,38 \\
\hline sub-5 & $3^{\circ} 51,978^{\prime}$ & $32^{\circ} 25,415^{\prime}$ & 91,9 & 2,70 & 0,16 & 99,64 & 0,20 & 0,00 & Areia & 2,48 & 0,74 \\
\hline sub-6 & $3^{\circ} 51,993^{\prime}$ & $32^{\circ} 25,457^{\prime}$ & 90,8 & 2,70 & 0,17 & 99,46 & 0,37 & 0,00 & Areia & 2,89 & 0,43 \\
\hline sub-7 & $3^{\circ} 51,993^{\prime}$ & $32^{\circ} 25,457^{\prime}$ & 91,9 & 2,10 & 0,10 & 99,87 & 0,03 & 0,00 & Areia & 2,64 & 0,67 \\
\hline
\end{tabular}

Localização, profundidades, ambiente sedimentar, granulometria, parâmetros estatísticos de Folk \& Ward (1957), classificação do diagrama triangular de Shepard (1954), teores de carbonato biodetrítico e matéria orgânica total da amostra da campanha FN-VII de Outubro de 2011.

\begin{tabular}{|c|c|c|c|c|c|c|c|c|c|c|c|c|c|}
\hline Estação & \begin{tabular}{|c} 
Latitude \\
(S)
\end{tabular} & $\begin{array}{c}\text { Longitude } \\
\text { (W) }\end{array}$ & \begin{tabular}{c|c|}
$\%$ \\
$\mathrm{CaCO} 3$ \\
\end{tabular} & \begin{tabular}{|c|} 
MO \\
total $\%$
\end{tabular} & Prof. & $\begin{array}{c}\% \\
\text { Gran }\end{array}$ & $\begin{array}{c}\% \\
\text { Areia }\end{array}$ & $\begin{array}{c}\% \\
\text { Silte }\end{array}$ & $\begin{array}{c}\% \\
\text { Argila }\end{array}$ & $\begin{array}{c}\text { Shepard } \\
\text { (1954) }\end{array}$ & $\begin{array}{c}\text { D. } \\
\text { Medio }\end{array}$ & Gr.Sel. & Ambiente \\
\hline $\begin{array}{l}\text { P1- st } \\
\text { laguna }\end{array}$ & $3^{\circ} 51,951^{\prime}$ & $32^{\circ} 25,561^{\prime}$ & 92,8 & 1,00 & $X$ & 0,03 & 99,87 & 0,10 & 0.00 & Areia & 2,49 & 0,42 & Mangue \\
\hline P1-st 4 & $3^{\circ} 51,961^{\prime}$ & $32^{\circ} 25,557^{\prime}$ & 93,1 & 0,97 & $X$ & 0.00 & 100.00 & 0.00 & 0.00 & Areia & 2,17 & 0,50 & Duna \\
\hline P1-st 8 & '51,972' & $32^{\circ} 25,553^{\prime}$ & 93,3 & 2,17 & $X$ & 0.00 & 100.00 & 0.00 & 0.00 & & 2,21 & 0,53 & \\
\hline P1-st 11 & $3^{\circ} 51,995^{\prime}$ & $32^{\circ} 25,542^{\prime}$ & 94,3 & 3,2 & $X$ & 0,57 & 99,43 & 0.00 & 0.00 & Areia & 2,28 & 0,62 & \\
\hline $\begin{array}{l}\text { P2- st } \\
\text { laguna }\end{array}$ & $3^{\circ} 51,930^{\prime}$ & $32^{\circ} 25,465^{\prime}$ & 36,70 & 19,67 & $x$ & 1,30 & 22,38 & 58,39 & 17,94 & $\begin{array}{c}\text { Silte } \\
\text { Arenoso }\end{array}$ & 5,23 & 2,32 & Mangue \\
\hline P2-st med & $3^{\circ} 51,933^{\prime}$ & $32^{\circ} 25,464^{\prime}$ & 89,8 & 3,67 & $x$ & 0,97 & 98,73 & 0,30 & 0.00 & Areia & 2,32 & 0,57 & Duna \\
\hline $\begin{array}{l}\text { P2- st } 1 \\
\text { duna }\end{array}$ & $3^{\circ} 51,936^{\prime}$ & $32^{\circ} 25,464^{\prime}$ & 90,10 & 3,23 & $x$ & 1,27 & 98,53 & 0,20 & 0.00 & Areia & 2,45 & 0,48 & Duna \\
\hline P2- st3 & $3^{\circ} 51,941^{\prime}$ & $32^{\circ} 25,462^{\prime}$ & 94,1 & 1,93 & $X$ & 0,07 & 99,87 & 0,07 & 0.00 & Areia & 2,47 & 0,45 & \\
\hline P2-st 6 & $51,949^{\prime}$ & $32^{\circ} 25,460^{\prime}$ & 94,8 & 2,27 & $X$ & 0.00 & 100.00 & 0.00 & 0.00 & & 2,34 &, 55 & \\
\hline C-1 & $3^{\circ} 52,006^{\prime}$ & $32^{\circ} 25,561^{\prime}$ & 94,3 & 2,9 & $X$ & 0,03 & 99,97 & 0.00 & 0.00 & Areia & 2,37 & 0,46 & \\
\hline C-2 & $3^{\circ} 51,970^{\prime}$ & $32^{\circ} 25,511^{\prime}$ & 94,5 & 2,63 & $X$ & 0,44 & 99,56 & 0.00 & 0.00 & Areia & 2,34 & 0,53 & Praia \\
\hline$C-3$ & $57^{\prime}$ & $5,487^{\prime}$ & 94,3 & 3,00 & $X$ & 0,13 & 99,87 & 0.00 & .00 & & 2,45 &, 52 & \\
\hline C-4 & $3^{\circ} 51,946^{\prime}$ & $32^{\circ} 25,426^{\prime}$ & 95,2 & 3,33 & $X$ & 0.00 & 100.00 & 0.00 & 0.00 & & 2,33 & 0,49 & Praia \\
\hline C-5 & $3^{\circ} 51,945^{\prime}$ & $32^{\circ} 25,397^{\prime}$ & 94,6 & 2,27 & $X$ & 0.00 & 100.00 & 0.00 & 0.00 & Areia & 2,48 & 0,54 & Praia \\
\hline & $3^{\circ} 51,949^{\prime}$ & $32^{\circ} 25,364^{\prime}$ & 94,5 & 3,43 & $X$ & 0.00 & 100.00 & 0.00 & 0.00 & & 2,52 & & Praia \\
\hline & $3^{\circ} 52,000^{\prime}$ & $32^{\circ} 25,554^{\prime}$ & 94,3 & 2,3 & 1,0 & 0.00 & 100.00 & 0.00 & 0.00 & & 2,26 & 56 & Antepraia \\
\hline $\mathrm{d}-2$ & $3^{\circ} 51,962^{\prime}$ & $32^{\circ} 25,457^{\prime}$ & 92,7 & 2,5 & 1,0 & 0,76 & 99,17 & 0,07 & 0.00 & Are & 1,93 & 0,94 & epraia \\
\hline sub-3 & & $32^{\circ} 25,397^{\prime}$ & 93,9 & 2,9 & 1,0 & 0,36 & 99,57 & 0,07 & 0.00 & & 2,29 & 0,75 & epraia \\
\hline & & $32^{\circ} 25,464^{\prime}$ & 88,7 & 2,23 & $X$ & 1,04 & 97,86 & 1,10 & 0.00 & & 2,87 & & Antepraia \\
\hline b-5 & $3^{\circ} 51,938^{\prime}$ & $32^{\circ} 25,468^{\prime}$ & 91,9 & 2,23 & 1,0 & 0,03 & 99,73 & 0,23 & 0.00 & & 2,32 & 0,45 & Antepraia \\
\hline sub-6 & $3^{\circ} 51,978^{\prime}$ & $32^{\circ} 25,415^{\prime}$ & 90,8 & 2,47 & 1,0 & 0,07 & 99,70 & 0,23 & 0.00 & Areia & 2,69 & 0,54 & Antepraia \\
\hline sub-7 & $3^{\circ} 51,993^{\prime}$ & $32^{\circ} 25,457^{\prime}$ & 90,6 & 1,73 & 1,0 & 0,07 & 99,93 & 0.00 & 0.00 & Areia & 2,28 & 0,60 & Antepraia \\
\hline
\end{tabular}




\section{APÊNDICE B}

\section{Tabelas com as informações da Análise da Fração Arenosa}

Frequencias relativas e índice de biogênicos marinhos (B.M.) dos constituintes identificados nas frações $0,500 \mathrm{~mm}$ (A) e 0,250mm (B) das amostras da campanha FN-I de Janeiro de 2010.

\begin{tabular}{|c|c|c|c|c|c|c|c|c|c|c|c|c|}
\hline \multicolumn{13}{|c|}{$\mathbf{A}$} \\
\hline Estação & MOL & FOR & CORAL & OBM & TBM & LEU & MPES & FROC & FVEG & OTR & TTR & B. M. $0.5 \mathrm{~mm}$ \\
\hline P2-stlag & 13,95 & 0,00 & 26,36 & 9,30 & 49,61 & 0,00 & 0,00 & 7,75 & 42,64 & 0,00 & 50,39 & $-0,01$ \\
\hline P1-st 4 & 32,73 & 4,85 & 18,18 & 32,12 & 87,88 & 2,42 & 1,82 & 3,64 & 4,24 & 0,00 & 12,12 & 0,76 \\
\hline P2- st 01 & 18,22 & 1,27 & 13,56 & 18,22 & 51,27 & 0,42 & 0,42 & 2,12 & 45,76 & 0,00 & 48,73 & 0,03 \\
\hline P2- st3 & 27,08 & 2,08 & 18,23 & 44,27 & 91,67 & 1,56 & 0,52 & 5,21 & 0,00 & 0,00 & 7,29 & 0,83 \\
\hline C-2 & 27,17 & 0,54 & 12,50 & 51,09 & 91,30 & 0,00 & 1,09 & 7,61 & 0,00 & 0,00 & 8,70 & 0,83 \\
\hline C-6 & 45,83 & 4,17 & 20,83 & 20,83 & 91,67 & 0,00 & 2,08 & 4,17 & 2,08 & 0,00 & 8,33 & 0,82 \\
\hline sub-1 & 22,49 & 1,44 & 9,09 & 44,98 & 77,99 & 1,44 & 4,78 & 15,79 & 0,00 & 0,00 & 22,01 & 0,56 \\
\hline sub-3 & 27,11 & 1,10 & 30,40 & 33,70 & 92,31 & 0,00 & 0,00 & 8,06 & 0,00 & 0,00 & 8,06 & 0,84 \\
\hline \multicolumn{13}{|c|}{ B } \\
\hline Estação & MOL & FOR & CORAL & OBM & TBM & LEU & MPES & FROC & FVEG & OTR & TTR & B.M 0.25mm \\
\hline P2-stlag & 18,71 & 0,65 & 42,58 & 24,52 & 86,45 & 0,65 & 0,00 & 9,68 & 3,23 & 0,00 & 13,55 & 0,73 \\
\hline P1-st 4 & 17,31 & 1,92 & 10,44 & 66,21 & 95,88 & 1,10 & 0,82 & 2,20 & 0,00 & 0,00 & 4,12 & 0,92 \\
\hline P2-st 01 & 21,21 & 1,82 & 23,03 & 46,06 & 92,12 & 0,61 & 0,00 & 4,24 & 3,03 & 0,00 & 7,88 & 0,84 \\
\hline P2- st3 & 29,21 & 2,62 & 16,48 & 42,70 & 91,01 & 0,75 & 0,37 & 7,87 & 0,00 & 0,00 & 8,99 & 0,82 \\
\hline C-2 & 17,81 & 6,39 & 24,89 & 44,06 & 93,15 & 0,46 & 0,46 & 5,94 & 0,00 & 0,00 & 6,85 & 0,86 \\
\hline C-6 & 21,92 & 4,79 & 43,84 & 20,55 & 91,10 & 0,34 & 0,34 & 8,22 & 0,00 & 0,00 & 8,90 & 0,83 \\
\hline sub-1 & 27,27 & 1,67 & 12,44 & 50,00 & 91,39 & 0,96 & 0,96 & 6,70 & 0,00 & 0,00 & 8,61 & 0,83 \\
\hline sub-3 & 19,79 & 3,82 & 34,72 & 33,68 & 92,01 & 1,04 & 0,00 & 6,60 & 0,00 & 0,00 & 7,64 & 0,85 \\
\hline
\end{tabular}

Legenda:

- MOL (Frag. Moluscos);

- FOR (Foramníferos);

- LEU (Leucita)

- CORAL (Frag. Corais);

- MPES (Minerais Pesados);

- OBM (Outros Biogênicos Marinhos)

- TBM (Total de Biogênicos Marinhos);

- FROC (Fragmentos de Rocha)

- FVEG (Fragmentos vegetais);

- OTR (Outros Terrígenos);

- TTR (Total de Terrígenos). 
Frequencias relativas e índice de biogênicos marinhos (B.M.) dos constituintes identificados nas frações $0,500 \mathrm{~mm}$ (A) e 0,250mm (B) das amostras da campanha FN-II de Abril de 2010.

\begin{tabular}{|c|c|c|c|c|c|c|c|c|c|c|c|c|}
\hline \multicolumn{13}{|c|}{ A } \\
\hline Estação & MOL & FOR & CORAL & OBM & TBM & LEU & MPES & FROC & FVEG & OTR & TTR & B. M. $0.5 \mathrm{~mm}$ \\
\hline P2- stlag & 1,56 & 0,00 & 0,78 & 5,47 & 7,81 & 0,00 & 0,00 & 0,78 & 91,41 & 0,00 & 92,19 & $-0,84$ \\
\hline P1-st 4 & 32,08 & 2,83 & 12,26 & 36,79 & 83,96 & 2,83 & 2,83 & 10,38 & 0,00 & 0,00 & 16,04 & 0,68 \\
\hline P2- st 01 & 15,75 & 0,00 & 15,75 & 15,07 & 46,58 & 0,00 & 0,00 & 0,68 & 52,74 & 0,00 & 53,42 & $-0,07$ \\
\hline P2- st3 & 32,03 & 1,56 & 12,50 & 42,97 & 89,06 & 1,56 & 0,78 & 5,47 & 3,13 & 0,00 & 10,94 & 0,78 \\
\hline C-2 & 29,32 & 0,75 & 19,55 & 39,85 & 89,47 & 1,50 & 2,26 & 6,02 & 0,75 & 0,00 & 10,53 & 0,79 \\
\hline C-6 & 39,41 & 3,81 & 25,42 & 24,58 & 93,22 & 0,00 & 0,00 & 5,51 & 0,00 & 0,00 & 5,51 & 0,89 \\
\hline sub-1 & 26,61 & 1,83 & 9,17 & 47,71 & 85,32 & 2,75 & 1,83 & 10,09 & 0,00 & 0,00 & 14,68 & 0,71 \\
\hline sub-3 & 19,59 & 1,22 & 35,51 & 38,37 & 94,69 & 0,00 & 0,00 & 5,31 & 0,00 & 0,00 & 5,31 & 0,89 \\
\hline sub-5 & 5,7 & 0,7 & 5,7 & 63,57 & 75,70 & 0,7 & 0,7 & 22,9 & 0,0 & 0,0 & 24,3 & 0,51 \\
\hline
\end{tabular}

\begin{tabular}{|c|c|c|c|c|c|c|c|c|c|c|c|c|}
\hline \multicolumn{13}{|l|}{ B } \\
\hline Estação & MOL & FOR & CORAL & OBM & TBM & LEU & MPES & FROC & FVEG & OTR & TTR & B.M $0.25 \mathrm{~mm}$ \\
\hline P2- stlag & 16,46 & 0,61 & 15,85 & 25,00 & 57,93 & 2,44 & 0,00 & 0,61 & 38,41 & 0,61 & 42,07 & 0,16 \\
\hline P1-st 4 & 19,34 & 0,73 & 9,49 & 57,30 & 86,86 & 5,11 & 0,73 & 7,30 & 0,00 & 0,00 & 13,14 & 0,74 \\
\hline P2 st 01 & 28,05 & 1,83 & 39,02 & 70,73 & 139,63 & 0,61 & 0,61 & 2,44 & 17,68 & 0,00 & 21,34 & 0,73 \\
\hline P2- st3 & 28,80 & 0,54 & 11,96 & 51,63 & 92,93 & 1,09 & 0,54 & 5,43 & 0,00 & 0,00 & 7,07 & 0,86 \\
\hline C-2 & 21,48 & 2,22 & 5,93 & 65,19 & 94,81 & 0,00 & 0,74 & 3,70 & 0,74 & 0,00 & 5,19 & 0,90 \\
\hline$C-6$ & 15,42 & 4,85 & 27,31 & 47,14 & 94,71 & 0,00 & 0,00 & 5,29 & 0,00 & 0,00 & 5,29 & 0,89 \\
\hline sub-1 & 14,16 & 0,88 & 11,50 & 62,83 & 89,38 & 2,65 & 0,88 & 6,19 & 0,00 & 0,88 & 10,62 & 0,79 \\
\hline sub-3 & 10,48 & 1,43 & 24,29 & 57,62 & 93,81 & 0,48 & 0,48 & 5,24 & 0,00 & 0,00 & 6,19 & 0,88 \\
\hline sub-5 & 21,3 & 2,2 & 22,2 & 41,33 & 87,1 & 1,8 & 0,9 & 10,2 & 0,0 & 0,0 & 12,9 & 0,74 \\
\hline
\end{tabular}

Legenda:

- MOL (Frag. Moluscos);

- FOR (Foramníferos);

- CORAL (Frag. Corais);

- OBM (Outros Biogênicos Marinhos);

- TBM (Total de Biogênicos Marinhos);

- QZO (Leucita);

- MPES (Minerais Pesados);

- FROC (Fragmentos de Rocha)

- FVEG (Fragmentos vegetais);

- OTR (Outros Terrígenos);

- TTR (Total de Terrígenos).

Frequencias relativas e índice de biogênicos marinhos (B.M.) dos constituintes identificados nas frações $0,500 \mathrm{~mm}$ (A) e $0,250 \mathrm{~mm}$ (B) das amostras da campanha FN-III de Junho de 2010.

\begin{tabular}{|c|c|c|c|c|c|c|c|c|c|c|c|c|}
\hline \multicolumn{13}{|c|}{$\mathbf{A}$} \\
\hline Estação & MOL & FOR & CORAL & OBM & TВM & LEU & MPES & FROC & FVEG & OTR & TTR & $\begin{array}{l}\text { B. M. } \\
0.5 \mathrm{~mm}\end{array}$ \\
\hline P2- stlag & 2,48 & 0,00 & 0,83 & 0,00 & 3,31 & 0,00 & 0,00 & 1,65 & 95,04 & 0,00 & 96,69 & $-0,93$ \\
\hline P1-st 4 & 26,87 & 0,00 & 11,94 & 48,51 & 87,31 & 3,73 & 2,99 & 5,97 & 0,00 & 0,00 & 12,69 & 0,75 \\
\hline P2- st 01 & 26,47 & 0,00 & 18,24 & 19,41 & 64,12 & 0,59 & 0,00 & 3,53 & 31,76 & 0,00 & 35,88 & 0,28 \\
\hline P2- st3 & 41,13 & 0,00 & 13,71 & 33,06 & 87,90 & 1,61 & 0,00 & 4,84 & 5,65 & 0,00 & 12,10 & 0,76 \\
\hline$C-2$ & 38,10 & 0,00 & 8,66 & 43,29 & 90,04 & 2,16 & 0,87 & 6,49 & 0,43 & 0,00 & 9,96 & 0,80 \\
\hline$C-6$ & 19,09 & 4,55 & 56,36 & 18,18 & 98,18 & 0,00 & 0,00 & 1,82 & 0,00 & 0,00 & 1,82 & 0,96 \\
\hline sub-1 & 27,97 & 1,69 & 12,71 & 41,53 & 83,90 & 2,54 & 5,93 & 7,63 & 0,00 & 0,00 & 16,10 & 0,68 \\
\hline sub-3 & 21,18 & 0,59 & 34,71 & 39,41 & 95,88 & 0,00 & 0,59 & 3,53 & 0,00 & 0,00 & 4,12 & 0,92 \\
\hline \multicolumn{13}{|c|}{ B } \\
\hline Estação & MOL & FOR & CORAL & OBM & TBM & LEU & MPES & FROC & FVEG & OTR & TTR & $\begin{array}{c}\text { B.M } \\
0.25 \mathrm{~mm}\end{array}$ \\
\hline P2- stlag & 5,92 & 1,18 & 26,63 & 30,77 & 64,50 & 0,59 & 0,00 & 0,59 & 34,32 & 0,00 & 35,50 & 0,29 \\
\hline P1-st 4 & 19,87 & 1,32 & 3,97 & 61,59 & 86,75 & 1,99 & 1,99 & 9,27 & 0,00 & 0,00 & 13,25 & 0,74 \\
\hline P2- st 01 & 15,60 & 2,29 & 27,52 & 42,66 & 88,07 & 0,92 & 0,00 & 1,83 & 9,17 & 0,00 & 11,93 & 0,76 \\
\hline P2- st3 & 32,43 & 2,03 & 13,51 & 43,92 & 91,89 & 2,70 & 1,35 & 4,05 & 0,00 & 0,00 & 8,11 & 0,84 \\
\hline C-2 & 28,06 & 1,53 & 10,20 & 54,59 & 94,39 & 1,02 & 0,51 & 4,08 & 0,00 & 0,00 & 5,61 & 0,89 \\
\hline C-6 & 27,48 & 3,82 & 17,56 & 46,56 & 95,42 & 0,00 & 0,00 & 4,58 & 0,00 & 0,00 & 4,58 & 0,91 \\
\hline sub-1 & 10,95 & 0,00 & 5,11 & 69,34 & 85,40 & 2,92 & 1,46 & 10,22 & 0,00 & 0,00 & 14,60 & 0,71 \\
\hline sub-3 & 21,32 & 2,94 & 32,35 & 40,44 & 97,06 & 0,00 & 0,74 & 2,21 & 0,00 & 0,00 & 2,94 & 0,94 \\
\hline
\end{tabular}

Legenda:

- MOL (Frag. Moluscos);

- FOR (Foramníferos);

- CORAL (Frag. Corais);

- OBM (Outros Biogênicos Marinhos);

- TBM (Total de Biogênicos Marinhos);

- LEU (Leucita).

- MPES (Minerais Pesados);

- FROC (Fragmentos de Rocha)

- FVEG (Fragmentos vegetais);

- OTR (Outros Terrígenos);

- TTR (Total de Terrígenos). 
Frequencias relativas e índice de biogênicos marinhos (B.M.) dos constituintes identificados nas frações $0,500 \mathrm{~mm}$ (A) e $0,250 \mathrm{~mm}$ (B) das amostras da campanha FN-IV de Outubro de 2010.

\begin{tabular}{|c|c|c|c|c|c|c|c|c|c|c|c|c|}
\hline \multicolumn{13}{|c|}{ A } \\
\hline Estação & MOL & FOR & CORAL & OBM & TBM & LEU & MPES & FROC & FVEG & OTR & TTR & $\begin{array}{c}\text { B. M. } \\
0.5 \mathrm{~mm}\end{array}$ \\
\hline P2- stlag & 1,13 & 0,00 & 0,56 & 0,00 & 1,69 & 0,56 & 0,00 & 0,00 & 97,74 & 0,00 & 98,31 & $-0,96$ \\
\hline P1-st 4 & 44,57 & 0,57 & 8,00 & 37,71 & 90,86 & 0,00 & 0,57 & 8,57 & 0,00 & 0,00 & 9,14 & 0,81 \\
\hline P2- st 01 & 14,17 & 0,83 & 13,33 & 5,83 & 34,17 & 0,83 & 0,00 & 3,33 & 61,67 & 0,00 & 65,83 & $-0,31$ \\
\hline P2- st3 & 0,00 & 1,89 & 32,08 & 54,72 & 88,68 & 0,00 & 0,00 & 7,55 & 3,77 & 0,00 & 11,32 & 0,77 \\
\hline C-2 & 20,67 & 1,68 & 22,91 & 40,22 & 85,47 & 3,35 & 0,56 & 10,61 & 0,00 & 0,00 & 14,53 & 0,71 \\
\hline$C-6$ & 16,83 & 5,94 & 58,42 & 16,83 & 98,02 & 0,00 & 0,00 & 1,98 & 0,00 & 0,00 & 1,98 & 0,96 \\
\hline sub-1 & 36,59 & 0,61 & 7,93 & 38,41 & 83,54 & 2,44 & 2,44 & 11,59 & 0,00 & 0,00 & 16,46 & 0,67 \\
\hline sub-3 & 26,52 & 0,76 & 25,00 & 41,67 & 93,94 & 0,00 & 0,76 & 5,30 & 0,00 & 0,00 & 6,06 & 0,87 \\
\hline sub-5 & 26,5 & 1,2 & 25,3 & 38,55 & 91,6 & 0,0 & 0,0 & 8,4 & 0,0 & 0,0 & 8,4 & 0,83 \\
\hline \multicolumn{13}{|c|}{ B } \\
\hline Estação & MOL & FOR & CORAL & OBM & TВM & LEU & MPES & FROC & FVEG & OTR & TTR & $\begin{array}{c}\text { B.M } \\
0.25 \mathrm{~mm}\end{array}$ \\
\hline P2- stlag & 6,64 & 0,88 & 7,08 & 3,98 & 18,58 & 0,00 & 0,00 & 0,00 & 81,42 & 0,00 & 81,42 & $-0,62$ \\
\hline P1-st 4 & 16,45 & 0,66 & 9,21 & 60,53 & 86,84 & 3,95 & 1,97 & 7,24 & 0,00 & 0,00 & 13,16 & 0,73 \\
\hline P2- st 01 & 17,14 & 0,71 & 24,29 & 37,14 & 79,29 & 1,43 & 0,00 & 2,86 & 16,43 & 0,00 & 20,71 & 0,58 \\
\hline P2- st3 & 27,70 & 2,82 & 25,35 & 40,85 & 96,71 & 0,00 & 0,00 & 2,82 & 0,47 & 0,00 & 3,29 & 0,93 \\
\hline C-2 & 17,78 & 4,44 & 29,33 & 44,00 & 95,56 & 1,33 & 0,44 & 2,67 & 0,00 & 0,00 & 4,44 & 0,91 \\
\hline C-6 & 15,04 & 6,02 & 41,35 & 36,09 & 98,50 & 0,00 & 0,00 & 1,50 & 0,00 & 0,00 & 1,50 & 0,97 \\
\hline sub-1 & 19,47 & 3,54 & 17,70 & 46,02 & 86,73 & 3,54 & 0,88 & 8,85 & 0,00 & 0,00 & 13,27 & 0,73 \\
\hline sub-3 & 18,37 & 5,10 & 22,45 & 47,96 & 93,88 & 0,00 & 1,02 & 5,10 & 0,00 & 0,00 & 6,12 & 0,87 \\
\hline sub-5 & 14,81 & 0,74 & 25,93 & 49,63 & 91,11 & 0,74 & 0,74 & 7,41 & 0,00 & 0,00 & 8,89 & 0,82 \\
\hline
\end{tabular}

Legenda:

- MOL (Frag. Moluscos);

- FOR (Foramníferos);

- CORAL (Frag. Corais);

- OBM (Outros Biogênicos Marinhos);

- TBM (Total de Biogênicos Marinhos);

- LEU (Leucita);

- MPES (Minerais Pesados)

- FROC (Fragmentos de Rocha);

- FVEG (Fragmentos vegetais);

- OTR (Outros Terrígenos);

- TTR (Total de Terrígenos).

Frequências relativas e índice de biogênicos marinhos (B.M.) dos constituintes identificados nas frações $0,500 \mathrm{~mm}$ (A) e $0,250 \mathrm{~mm}$ (B) das amostras da campanha FN-V de março de 2011.

\begin{tabular}{lccccccccccccc}
\hline \multicolumn{10}{c|}{ A } \\
Estação & MOL & FOR & CORAL & OBM & TBM & LEU & MPES & FROC & FVEG & OTR & TTR & B. M. 0,5mm \\
\hline P2- st laguna & 0,92 & 0,46 & 1,83 & 0,00 & 3,21 & 0,00 & 0,00 & 0,46 & 96,33 & 0,00 & 96,79 & $\mathbf{- 0 , 9 4}$ \\
P1-st 4 & 45,90 & 0,82 & 20,49 & 22,95 & 90,16 & 6,56 & 0,00 & 3,28 & 0,00 & 0,00 & 9,84 & $\mathbf{0 , 8 0}$ \\
C-6 & 30,10 & 8,74 & 41,26 & 15,05 & 95,15 & 0,00 & 0,49 & 4,37 & 0,00 & 0,00 & 4,85 & $\mathbf{0 , 9 0}$ \\
sub-1 & 19,09 & 0,45 & 21,36 & 49,09 & 90,00 & 0,91 & 2,27 & 6,82 & 0,00 & 0,00 & 10,00 & $\mathbf{0 , 8 0}$ \\
sub-5 & 11,17 & 1,12 & 20,67 & 55,87 & 88,83 & 1,68 & 2,23 & 6,70 & 0,56 & 0,00 & 11,17 & $\mathbf{0 , 7 8}$ \\
\hline
\end{tabular}

\begin{tabular}{lccccccccccccc}
\hline \multicolumn{10}{c|}{ B } \\
\hline Estação & MOL & FOR & CORAL & OBM & TBM & LEU & MPES & FROC & FVEG & OTR & TTR & B.M 0,25mm \\
\hline P2- st laguna & 5,21 & 1,39 & 23,26 & 0,00 & 29,86 & 1,04 & 0,00 & 3,13 & 65,97 & 0,00 & 70,14 & $\mathbf{- 0 , 4 0}$ \\
P1-st 4 & 13,16 & 3,16 & 28,42 & 45,79 & 90,53 & 4,74 & 1,05 & 3,68 & 0,00 & 0,00 & 9,47 & $\mathbf{0 , 8 1}$ \\
C-6 & 21,97 & 3,59 & 39,01 & 29,15 & 93,72 & 0,90 & 0,90 & 4,48 & 0,00 & 0,00 & 6,28 & $\mathbf{0 , 8 7}$ \\
sub-1 & 11,36 & 0,73 & 9,89 & 67,40 & 89,38 & 4,40 & 1,10 & 5,13 & 0,00 & 0,00 & 10,62 & $\mathbf{0 , 7 9}$ \\
sub-5 & 26,85 & 2,31 & 31,94 & 30,56 & 91,67 & 1,85 & 0,46 & 6,02 & 0,00 & 0,00 & 8,33 & $\mathbf{0 , 8 3}$ \\
\hline
\end{tabular}

Legenda:

- MOL (Frag. Moluscos);

- FOR (Foramníferos);

- CORAL (Frag. Corais);

- LEU (Leucita);

- OBM (Outros Biogênicos Marinhos);

- TBM (Total de Biogênicos Marinhos);

- MPES (Minerais Pesados);

- FROC (Fragmentos de Rocha);

- FVEG (Fragmentos vegetais);

- OTR (Outros Terrígenos);

- TTR (Total de Terrígenos). 
Frequencias relativas e índice de biogênicos marinhos (B.M.) dos constituintes identificados nas frações $0,500 \mathrm{~mm}$ (A) e $0,250 \mathrm{~mm}$ (B) das amostras da campanha FN-VI de Julho de 2011.

\begin{tabular}{lcccccccccccc}
\hline \multicolumn{10}{c|}{ A } \\
\hline Estação & MOL & FOR & CORAL & OBM & TBM & LEU & MPES & FROC & FVEG & OTR & TTR & B. M. 0.5mm \\
\hline P2- st laguna & 53,94 & 0,00 & 16,36 & 60,61 & 2,42 & 0,61 & 2,42 & 5,45 & 1,21 & 0,00 & 97,58 & $-\mathbf{0 , 9 5}$ \\
P1-st 4 & 44,23 & 0,00 & 5,77 & 41,35 & 91,35 & 2,88 & 0,96 & 3,85 & 0,96 & 0,00 & 8,65 & $\mathbf{0 , 8 3}$ \\
C-6 & 35,21 & 1,88 & 38,50 & 21,13 & 96,71 & 0,00 & 0,47 & 2,82 & 0,00 & 0,00 & 3,29 & $\mathbf{0 , 9 3}$ \\
sub-1 & 38,20 & 0,43 & 11,59 & 42,92 & 93,13 & 0,43 & 1,72 & 3,86 & 0,86 & 0,00 & 6,87 & $\mathbf{0 , 8 6}$ \\
sub-5 & 26,40 & 5,62 & 16,85 & 44,94 & 93,82 & 0,00 & 1,12 & 5,06 & 0,00 & 0,00 & 6,18 & $\mathbf{0 , 8 8}$ \\
\hline
\end{tabular}

\begin{tabular}{lccccccccccccc}
\hline \multicolumn{10}{c}{ B } \\
\hline Estação & MOL & FOR & CORAL & OBM & TBM & LEU & MPES & FROC & FVEG & OTR & TTR & B.M 0.25mm \\
\hline P2- st laguna & 2,24 & 0,45 & 8,07 & 11,66 & 22,42 & 0,45 & 0,00 & 3,14 & 73,99 & 0,00 & 77,58 & $\mathbf{- 0 , 5 5}$ \\
P1-st 4 & 10,75 & 0,93 & 5,14 & 69,16 & 85,98 & 2,80 & 1,87 & 9,35 & 0,00 & 0,00 & 14,02 & $\mathbf{0 , 7 2}$ \\
C-6 & 18,22 & 3,11 & 36,89 & 36,44 & 94,67 & 0,00 & 0,44 & 4,89 & 0,00 & 0,00 & 5,33 & $\mathbf{0 , 8 9}$ \\
sub-1 & 17,95 & 1,28 & 14,10 & 55,98 & 89,32 & 2,99 & 0,43 & 7,26 & 0,00 & 0,00 & 10,68 & $\mathbf{0 , 7 9}$ \\
sub-5 & 20,63 & 3,59 & 22,87 & 46,19 & 93,27 & 0,45 & 0,00 & 6,28 & 0,00 & 0,00 & $\mathbf{6 , 7 3}$ & $\mathbf{0 , 8 7}$ \\
\hline
\end{tabular}
Legenda:

- MOL (Frag. Moluscos);

- $\quad$ FOR (Foramníferos);

- $\quad$ CORAL (Frag. Corais);

- $\quad$ OBM (Outros Biogênicos Marinhos);

- $\quad$ TBM (Total de Biogênicos Marinhos);

- $\quad$ LEU (Leucita);

- $\quad$ MPES (Minerais Pesados);

- $\quad$ FROC (Fragmentos de Rocha);

- $\quad$ FVEG (Fragmentos vegetais);

- $\quad$ OTR (Outros Terrígenos);

- $\quad$ TTR (Total de Terrígenos).

Frequencias relativas e índice de biogênicos marinhos (B.M.) dos constituintes identificados nas frações $0,500 \mathrm{~mm}$ (A) e $0,250 \mathrm{~mm}$ (B) das amostras da campanha FN-VII de Outubro de 2011.

\begin{tabular}{|c|c|c|c|c|c|c|c|c|c|c|c|c|}
\hline \multicolumn{13}{|c|}{$\mathbf{A}$} \\
\hline Estação & MOL & FOR & CORAL & OBM & TBM & LEU & MPES & FROC & FVEG & OTR & TTR & B. M. $0,5 \mathrm{~mm}$ \\
\hline P2- st laguna & 0,56 & 0,56 & 2,82 & 0,00 & 3,95 & 0,00 & 0,00 & 0,00 & 96,05 & 0,00 & 96,05 & $-0,92$ \\
\hline P1-st 4 & 53,11 & 1,13 & 12,99 & 23,16 & 90,40 & 0,00 & 2,26 & 7,34 & 0,00 & 0,00 & 9,60 & 0,81 \\
\hline C-6 & 19,65 & 8,67 & 52,60 & 19,08 & 100,00 & 0,00 & 0,00 & 0,00 & 0,00 & 0,00 & 0,00 & 1,00 \\
\hline sub-1 & 38,31 & 0,34 & 25,76 & 30,85 & 95,25 & 0,34 & 0,68 & 3,73 & 0,00 & 0,00 & 4,75 & 0,91 \\
\hline sub-5 & 13,08 & 0,93 & 19,63 & 61,68 & 95,33 & 1,87 & 0,00 & 2,80 & 0,00 & 0,00 & 4,67 & 0,91 \\
\hline \multicolumn{13}{|c|}{ B } \\
\hline Estação & MOL & FOR & CORAL & OBM & TBM & LEU & MPES & FROC & FVEG & OTR & TTR & B.M $0,25 \mathrm{~mm}$ \\
\hline P2- st laguna & 2,47 & 1,41 & 14,84 & 3,89 & 22,61 & 0,35 & 0,35 & 0,35 & 75,97 & 0,35 & 77,39 & $-0,55$ \\
\hline P1-st 4 & 24,58 & 0,42 & 12,50 & 55,00 & 92,50 & 1,25 & 0,42 & 5,83 & 0,00 & 0,00 & 7,50 & 0,85 \\
\hline$C-6$ & 21,18 & 5,88 & 34,12 & 38,43 & 99,61 & 0,00 & 0,00 & 0,39 & 0,00 & 0,00 & 0,39 & 0,99 \\
\hline sub-1 & 17,11 & 2,01 & 30,54 & 48,32 & 97,99 & 0,00 & 0,34 & 1,34 & 0,00 & 0,34 & 2,01 & 0,96 \\
\hline sub-5 & 16,28 & 3,72 & 28,84 & 46,98 & 95,81 & 0,00 & 0,47 & 3,72 & 0,00 & 0,00 & 4,19 & 0,92 \\
\hline
\end{tabular}

Legenda:

- MOL (Frag. Moluscos);

- FOR (Foramníferos);

- CORAL (Frag. Corais);

- LEU (Leucita);

- OBM (Outros Biogênicos Marinhos);

- TBM (Total de Biogênicos Marinhos);

- MPES (Minerais Pesados);

- FROC (Fragmentos de Rocha);

- FVEG (Fragmentos vegetais);

- OTR (Outros Terrígenos);

- TTR (Total de Terrígenos). 